\title{
The Neurology of Cerebral Palsy
}

\author{
T. T. S. INGRAM* \\ From the Department of Child Life and Health, University of Edinburgh
}

Cerebral palsy is an inclusive term used to describe a number of chronic non-progressive disorders of motor function, which occur in young children as a result of disease of the brain. Excluded by this definition are transient disorders of motor function, such as those that may occur in encephalitis or meningitis; disorders such as spina bifida, in which the disturbance of motor function is predominantly due to disease of the spinal cord; and degenerative conditions, including progressive demyelinations.

The diseases of the brain which cause cerebral palsy are by definition non-progressive, but must be thought of as giving rise to a clinical picture that changes. As the child's nervous system develops the clinical findings he manifests will change too (Crothers and Paine, 1959).

The effects of lesions of the hemispheres differ not only according to their nature, their situation, and their extent, as they do in the adult, but also according to the age at which they were sustained and the neurological maturation of the child at the time he is examined (Byers, 1941 ; Ingram, 1964a, b). It is because the child's nervous system, damaged or undamaged, is still developing and the child is acquiring new motor, linguistic, adaptive, and social skills that the methods of diagnosis used by the paediatric neurologist have to differ from those employed with adult patients. They must take account of the fact that, whereas an acquired lesion in the brain of an adult may be expected to produce loss of acquired skills, a similar lesion in the brain of a young child may or may not delay the attainment of a particular milestone of development. For example, it is unreasonable to expect a child of 6 months to be rendered dysphasic as a result of an extensive fronto-temporal lesion in the dominant hemisphere. Dysphasia implies loss of the ability to use language, and the child aged 6 months has not yet acquired language. In such a case there may or may not be subsequent retardation of speech development (Ingram and Barn, 1961).

* Address: 17 Hatton Place, Edinburgh 9.
The fact that the clinical findings in cerebral palsy do change, especially in young patients, means that the same sequential clinical studies used in child patients with degenerative or transient disorders of the central nervous system must be employed in those who suffer from cerebral palsy. Cerebral palsy is part of child neurology (Meyers, 1958; Ingram, 1966).

\section{Principles and Methods of Diagnosis}

The clinician faced with the problem of the diagnosis of a lesion of the central nervous system in a mature adult thinks in terms of the nature of the disease process, its localization, its extent, and its likely progress. He considers what effects the lesion is likely to have on the individual in terms of the further dissolution or recovery of function. The neurologist who deals with the child has to be aware of the fact that, in the early months particularly, quite extensive abnormalities of the hemispheres may not be manifest by changes in the behaviour of the child. In the first 6 to 8 weeks of life, for example, even anencephalic babies may behave relatively normally if they survive (Peiper, 1964). It is for this reason that it is so rash to predict that a baby who appears to have made a good recovery from apparent birth injury by the age of a few weeks will later be normal. Much is still to be learnt about the prognostic significance of abnormalities of behaviour in the newborn period (Prechtl and Beintema, 1964).

The first manifestations of hemisphere lesions in the infant may be that he is late in reaching some of the milestones of motor, linguistic, adaptive, and social behaviour. Developmental diagnosis-the ages at which the patient has reached particular milestones of development-is thus of great importance (Gesell and Amatruda, 1941; Thomas and Saint Anne Dargassies, 1952).

Developmental diagnosis may be applied both to the whole child and to his various parts. It is important to know when children could first sit up, with or without support, say their first intelligible words, feed themselves, and play successfully with 


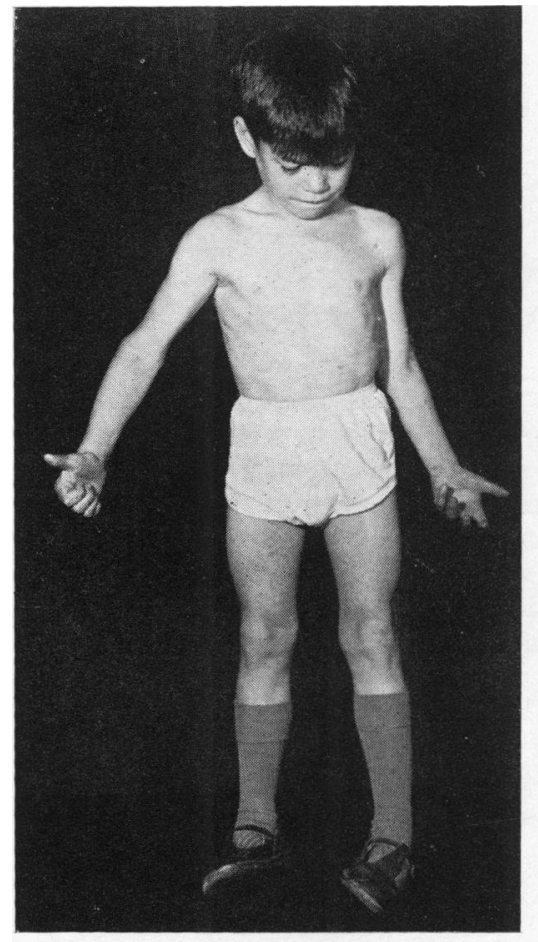

(a)

children of the same age; but a consideration of the function of various parts of the body may also be rewarding. It may be found, for example, that a child can reach accurately using the pincer grasp between the thumb and forefinger with the right hand but not with the left, and that he cannot release the grasp voluntarily in the left hand, though he has been able to do this from the age of 8 months in the right. In such a situation the motor function of the left hand can be regarded as being immature and its motor function slow in developing. Similarly, a normal development of manipulative function in the upper limbs may be in striking contrast to retarded development of locomotion, and might suggest that functional development of the lower limbs had been retarded to a greater extent than that of the upper limbs. This is the situation in diplegic cerebral palsy or in infantile muscular dystrophy.

As well as giving a great deal of information about the nature, extent, and severity of neurological impairment in cerebral palsy, developmental diagnosis is also useful prognostically. For example, an assessment of the ages at which a child has first sat up with support, then without support, crawled, and

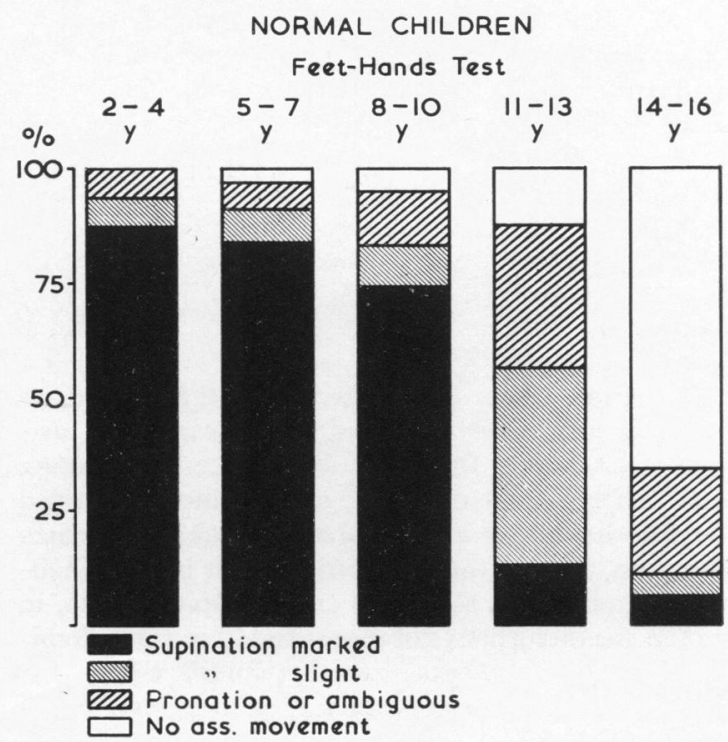

(b)

FIG. $1 a$ and $b .-$ The 'feet-hands test' of the Fogs. (a) The left upper limb, which in this patient is less mature neurologically, shows more associated involuntary movement when the child is asked to walk with his feet inverted. (b) Chart to show proportion of normal children at different ages displaying supination, or other involuntary movement of hand, with this test.

stood with support may often allow a prediction to be made about the likely age at which independent walking will be achieved (Bobath and Bobath, 1962).

Most of the information about the child's development must necessarily be obtained by questioning parents about the ages at which their children reached particular milestones, and additional information can be obtained from baby books, old photographs, or from hospital and clinical notes made in earlier years.

While a strange clinic environment often inhibits the child's behaviour at the time of a first interview, it is usually possible to obtain a fairly clear idea of the level of motor maturation that the child has reached, and what level of motor maturation has been reached by a particular limb. The assessment of motor maturation is becoming increasingly precise as standardized tests are developed (Bergès and Lézine, 1965; Fog and Fog, 1963; D. H. Stott, 1965, personal communication). (Fig. la and b.)

The assessment of motor maturation is reached both positively and negatively: positively by noting the motor achievements of the child, for example his ability to reach for objects, sit without support, 
crawl, and stand with support; negatively by considering the extent to which reflex behaviour patterns characteristic of the young infant have been inhibited by the development of higher nervous centres. Thus the paediatrician is interested to find out whether the stepping, Moro, lip, and grasp reflexes persist or have disappeared. In the past 30 years, largely because of the interest shown by Peiper (1964), Thomas, Chesni, and Saint Anne Dargassies (1960), Prechtl and Beintema (1964), Bobath and Bobath (1956), Oppé and Paine (1966), and other authors, a systematic study of infantile reflexes in normal children and in patients who suffer from a variety of disorders of the central nervous system has taken place, and a much more accurate grading of maturation on the basis of the persistence and inhibition of these reflexes has become possible (Fig. 2). Some reflexes tend to be much more easily elicited in one type of cerebral palsy than in another, and for this reason they will be discussed in more detail when the various types are considered (Paine, Brazelton, Donovan, Drorbaugh, Hubbell, and Sears, 1964).

\section{History Taking and Examination}

Since paediatricians and neurologists began to take a serious interest in cerebral palsy (Crothers and Paine, 1959; Hansen, 1960; Denhoff and Holden, 1951), more has been learnt about the predisposing and precipitating causes of cerebral palsy, and this influences the type of questions to be asked in taking the history. Attention is no longer practically confined to what happened in the perinatal period; a more detailed family history is taken as to the reproductive history of the mother, and of her sisters, mother, and aunts (Ingram and Russell, 1961; Ingram, 1964b; Drillien, Ingram, and Russell, 1964).

The history is usually taken from the mother, though it is helpful if she can be supported by either her husband, her mother, or her mother-in-law during the course of history taking. The order of history taking and examination matters less than the order in which it is recorded. It is a great help if histories and examinations are routinely written out in the same sequence; not only does this lessen the risk of important items being omitted but it facilitates ease of reference later on.

\section{Classification of Cerebral Palsy}

The work of Sigmund Freud (1897) marked a significant advance in the study of cerebral palsy and particularly in the definition of clinical syndromes and their classification. $\mathrm{He}$ pointed out that cerebral palsy was the end result of a number of different disease processes, and that the nature of the

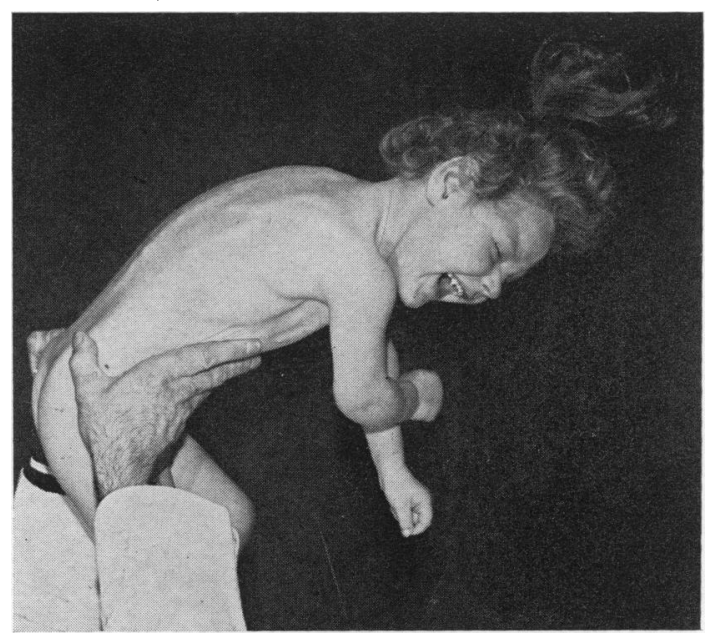

FIG. 2.-Abnormal 'parachute' reaction in a child suffering from mild cerebral palsy. When tilted forwards the upper limbs should flex, extend at the elbows and wrists, and the hands open-as if to protect the head from hitting the ground.

original disease process would not necessarily be inferred from the later neuropathological findings. Classification on the basis of neuropathological findings was therefore likely to be unrewarding.

Since the clinical history and examination could not reliably identify disease processes responsible for cerebral palsy in the majority of cases, classification on the basis of the presumed cause of the condition, as had been suggested (Sachs and Hausman, 1926), was also impractical. More recent work has supported Freud's conclusions, for it is shown how difficult it may be to distinguish on clinical grounds (and even after radiological and other investigations) when cerebral palsy has been the result of developmental malformations of the brain and when it has been caused by perinatal injury (Minkowski, 1955; Courville, 1953, 1954; Norman, 1963). The need for caution in attributing 'a cause' to the brain damage in these patients has been further emphasized by the demonstration that there appear to be predisposing factors, probably genetically determined, which make some individuals susceptible to cerebral palsy as a result of perinatal injury to the brain (Drillien, Ingram, and Russell, 1962).

Freud hoped that as methods of clinical investigation improved precise diagnosis of disease entities within the group of patients who suffered from cerebral palsy would become increasingly possible. His hopes have been fulfilled to some extent; for example, there is a known association between maternal rubella occurring during the first two or 


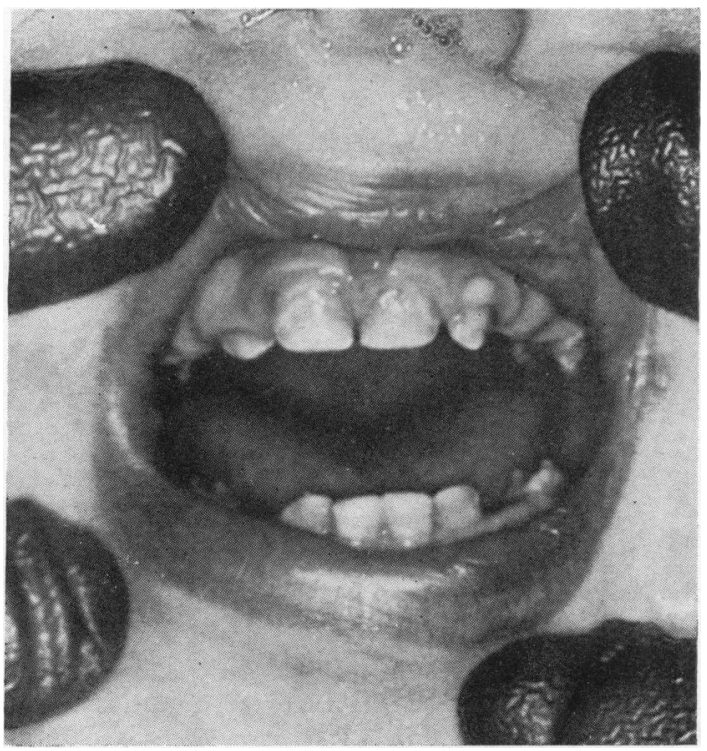

FIG. 3.-Pigmentation and enamel defects, best seen on the lateral incisors, in a child suffering from dyskinesia as a result of kernikterus at an estimated 8 months' gestational age.

three months of gestation and rubella retinopathy and encephalopathy occurring in the foetus. The finding of the characteristic retinal pigmentation of rubella retinopathy in an affected patient makes the retrospective diagnosis of rubella embryopathy virtually certain (Stark, 1966). Similarly the finding of rhesus incompatibility between mother and patient, with a history suggestive of kernikterus and clinical findings of congenital choreoathetosis with defective upward movement of the eyes, high-tone deafness, and enamel defects of the teeth (Fig. 3), allows a diagnosis to be made of dyskinetic cerebral palsy attributable to rhesus incompatibility (Crothers, 1921; Byers, 1942; Evans and Polani, 1950; Forrester and Miller, 1955; Plum, 1965). The clinical picture of more or less symmetrical paresis of the limbs, more marked in the lower limbs than in the upper, and usually associated with rigidity or spasticity, which is found in a high proportion of babies of small birth weight, is also characteristic, though it is much more difficult to identify the 'cause' in this example (Drillien, 1964; Russell, 1960a).

Freud classified patients on the basis of clinical findings. $\mathrm{He}$ distinguished between unilateral cerebral palsy or hemiplegia, in which paresis usually accompanied by spasticity might be complicated by the presence of involuntary movement, and bilateral cerebral palsy. The bilateral cerebral palsies or 'diplegias' comprised generalized rigidity-or Little's disease-in which there was more or less symmetrical paresis of voluntary movement, more severe in the lower limbs than in the upper, accompanied by spasticity or rigidity in the lower limbs, and dwarfing. The difference between paraplegic rigidity and generalized rigidity was one of degree and extent rather than of kind.

Bilateral hemiplegia was the name given to bilateral paresis of the limbs which might be symmetrical or asymmetrical and which affected the upper limbs more severely than the lower limbs. Patients with bilateral hemiplegia almost invariably had involvement of the bulbar musculature and a high proportion were severely microcephalic, mentally retarded, and epileptic. Patients with generalized chorea or double athetosis were those in whom involuntary movements and inappropriate changes of muscle tone in the course of voluntary movement were the major disabilities. Freud foresaw that patients with generalized chorea and double athetosis might be better placed in the major category separate from cerebral diplegia, and he speculated as to the need for a category of 'congenital ataxia', of which a few case reports had appeared. He felt, however, that these might still be atypical types of progressive spinal cerebellar disease to which attention had recently been attracted by Friedreich (1863, 1876), and Freud (1891, 1893, 1897). Within 10 years of the publication of Freud's major paper, Batten $(1903,1905,1907)$ had established the existence of a condition of nonprogressive congenital ataxia, attributable usually to developmental malformations or perinatal injury of the cerebellum and its connexions.

As interest in the therapy of cerebral palsy developed other classifications evolved. In particular, classification by neurological syndromes tended to be replaced, especially in the United States, by classification according to the state of muscle tone and the presence or absence of incoordination and involuntary movement in the limbs. Thus Phelps (1941, 1943, 1948) recognized 5 major categories of cerebral palsy with, (1) spasticity, (2) athetosis, (3) rigidity, (4) tremor, (5) ataxia.

This classification has been influential, and many others are based to a large extent upon it (Perlstein, 1952; Minear, 1956; Little Club, 1959). The objections to classification primarily on the basis of changes in muscle tone are that muscle tone in individual patients varies greatly according to emotional state, environmental temperature, alertness, and particularly posture. Young babies who suffer from a bilateral cerebral palsy more severe in the lower limbs than the upper ('diplegia' or 'Little's 

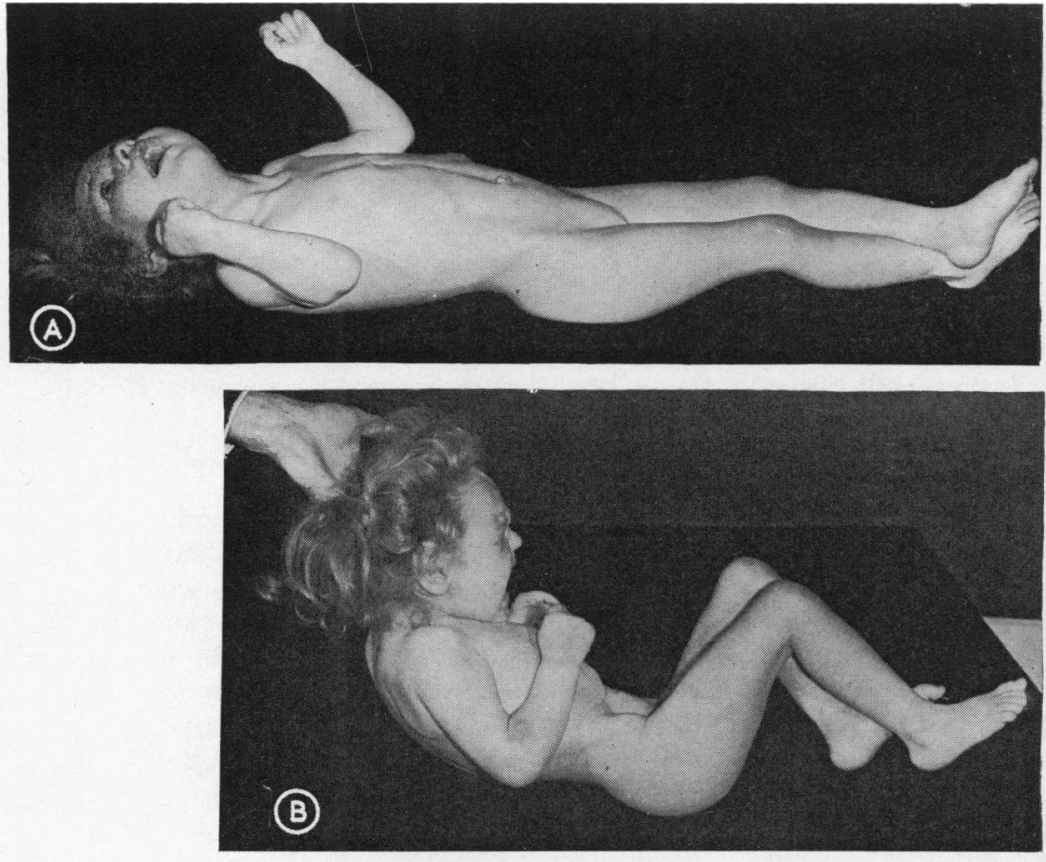

FIG. 4A, B, C.-Characteristic postures in a child with mixed cerebral palsy, dyskinesia predominating in the upper limbs, and diplegic paresis in the lower. (A) and (B) demonstrate the effect of head extension and flexion on the position of the limbs when the child lies supine. (C) shows the child placed in the erect position; an increase in anti-gravity hypertonus causes scissoring and extension of the lower limbs.

disease') are often hypotonic when lying in the prone position, but show generalized rigidity when placed in the erect position. A more serious objection is that classification primarily on the basis of alterations of muscle tone takes no account of the changing clinical picture which is observed as patients mature. Thus patients who suffer from diplegia are frequently hypotonic in the first months of life, then show variable muscle tone according to changes in position, and finally reach a stage in which rigidity and spasticity predominate. Because of these drawbacks, classification on the basis of neurological syndromes has returned to favour increasingly in recent years, though some clinicians have adopted compromises between classification on the basis of mucle tone and of neurological syndromes (Perlstein, 1952; Balf and Ingram, 1955; Minear, 1956; Crothers and Paine, 1959).

Increasing attention has been paid to reflex changes in posture which occur in different types of cerebral palsy (Bobath and Bobath, 1962). Characteristic positions of the limbs and trunk have been described in children with cerebral palsy either at rest, or when they are placed in particular

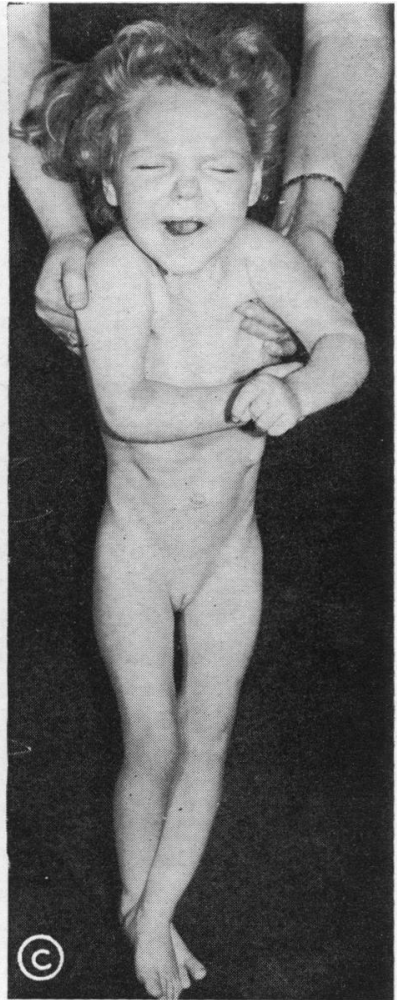

positions, and it has been suggested that in the future it may be possible to define clinical categories in terms of 'patternological diagnosis' rather than in terms of classical neurological syndromes (MilaniComparetti, 1965) (Fig. 4).

The classification used in Edinburgh, and which will be used in this article, is shown in Table I. This derives from that of Freud, but the term diplegia is reserved for patients with more or less symmetrical paresis of the limbs, affecting the lower limbs more severely than the upper; and bilateral hemiplegia, ataxia, and dyskinesia become major categories. Patients are further classified according to the stage of the evolution of their cerebral palsy, and the extent and severity of motor involvement in the limbs. A category for mixed and other types of cerebral palsy is provided, but most of those who cannot be classified in the major categories are either too young for accurate diagnosis to be possible, or have combinations of dyskinesia and diplegia or hemiplegia and ataxia (Ingram, 1964a).

\section{Hemiplegia}

Hemiplegia is of congenital origin in approximately two-thirds of young children with this condition in 
TABLE I

Classification of Cerebral Palsy

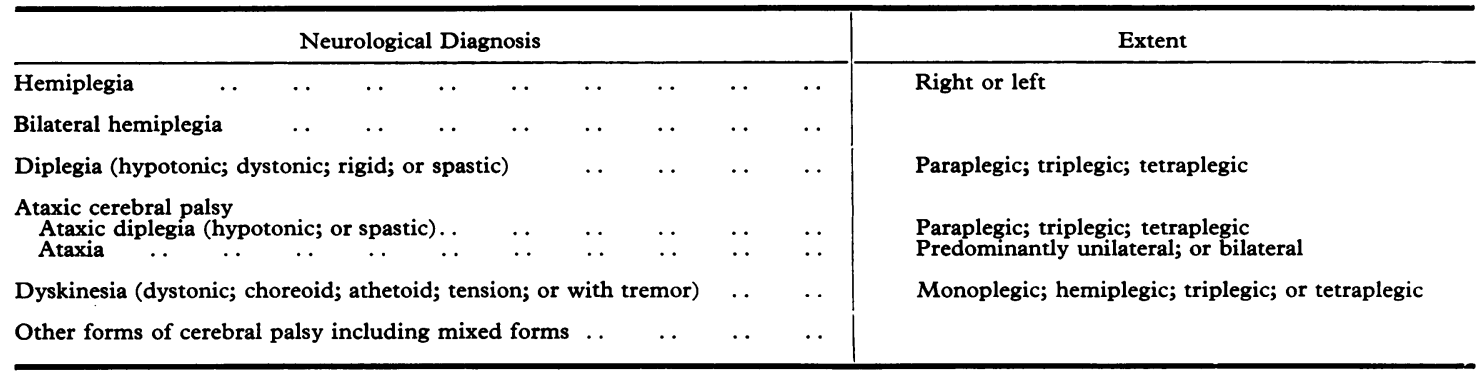

most series (Hood and Perlstein, 1955; Perlstein and Hood, 1954; Eastman and DeLeon, 1955; Eastman, Kohl, Maisel, and Kavaler, 1962; Crothers and Paine, 1959; Mitchell, 1961a). Though developmental malformation of the brain, particularly hypoplasia or even agenesis of a hemisphere, may be responsible for a minority of cases of congenital hemiplegia, the majority appear to be the result of brain damage sustained in the perinatal period. Commonly there are multiple abnormalities of late pregnancy, labour, delivery, and the neonatal period, so that it is often difficult to assess the extent to which the condition is the result of hypoxia in pregnancy, trauma during labour or delivery, or brain damage from neonatal apnoea. More are immature by birth weight and more are post-mature by dates than expected, and there is an excess of babies with birth weights above $3,850 \mathrm{~g}$. $\left(8 \frac{1}{2} \mathrm{lb}\right.$.) (Eastman et al., 1962; Ingram, 1964b).

In about one-third of hemiplegic children the cause is disease or trauma affecting the brain after birth, usually in the first 3 years of life and most commonly in the first year. Acquired hemiplegia may result from cerebral thrombophlebitis or sinus thrombosis complicating middle ear disease, or respiratory tract infections, or dehydrating conditions such as gastro-enteritis (Byers and Hass, 1933; Mitchell, 1952). Para-infectious encephalopathies, for example those complicating measles, chickenpox, and other virus infections and which may also follow vaccination or immunization against diphtheria, tetanus, whooping cough, or typhoid, are other major causes of acquired hemiplegia (Sandifer, 1962; Miller and Stanton, 1954; Miller, Stanton, and Gibbons, 1956). Other causes are encephalopathies of unknown origin (Lyon, Dodge, and Adams, 1961) or those that occur with lead poisoning, with overwhelming infections, or with meningitis, particularly pneumococcal, influenzal, or tuberculous (Todd and Neville, 1964; Wood, 1964; Nyhan and Richardson, 1963; Hutchison and
Kovacs, 1963; Bax and Mitchell, 1962; A. Holzel, 1966, personal communication; Smith, 1954). A less common cause is thrombosis of the internal carotid artery, which may occur in cyanotic congenital heart disease, or following trauma to the carotid artery, usually after a penetrating injury has affected the artery in the tonsillar fossa (Braudo, 1956; Till and Hoare, 1962; Goldstein and Burgess, 1958; Brandt, 1962).

Patients who suffer from congenital hemiplegia show poverty of movement in the affected limbs (and commonly the face) without spasticity for a period of two to three months. When the child is about 3 months the mother may observe that the infant is moving the affected upper limb much less than the contralateral one, and in particular that the paretic hand is not opened as the other one is. It is only about this age that true spasticity is apparent on examination (Byers, 1941).

The appearance of acquired hemiplegia is usually preceded by a seizure, and it is usually after the seizure, which may be unilateral or bilateral, that the affected limbs are noted to be abnormal. Paresis is maximal immediately after the seizure; there is poverty of movement and flaccidity in the arm, leg, and face following the brain injury and then a gradual return of some voluntary movement. The return is characteristically first in the proximal parts of the limbs and spreads gradually, distally. The order in which movements return is very similar to the order in which they are acquired in normal infants. Spasticity appears only after 2 or 3 weeks and noticeably increases in severity in the ensuing 6 to 8 weeks. During this time the affected upper limb takes up the characteristic posture of adduction, flexion, and internal rotation of the shoulder, semiflexion at the wrist, and pronation of the forearm with flexion at the wrists and fingers over the adducted thumb. The lower limb tends to be semiflexed and adducted, and internally rotated at the hip, semiflexed at the knee, and the foot is 
plantar flexed. There is often either associated varus or valgus deformity of the foot (Mitchell, 1962; Wuillamier, 1882; Glenting, 1963; Twitchell, 1951, 1957, 1958).

The extent of recovery and the time it takes to occur vary greatly in acquired hemiplegia, and it is more difficult to predict the degree of function which will eventually be achieved (Bax, 1962). Similarly in congenital hemiplegia, voluntary movements are acquired later in the hemiplegic hand than in the normal hand, but it is difficult to predict with any reliability those movements that are likely to be acquired and those that are unlikely to be acquired before the child is about 1 year of age.

In mildly affected patients the voluntary movements which are absent are those that are the last to be acquired in the course of normal child development, for example, abduction of the thumb and full supination of the forearm. In more severe cases, movements which the normal child acquires earlier may be lost, e.g. the ability to extend the fingers voluntarily. In very severely affected patients there may be virtually no use of the paretic hand. From the functional point of view it is convenient to grade severity as follows:

Mildly affected, those who use the hemiplegic hand independently.

Moderately severely affected, those who use the paretic hand as an assistant to the other.

Severely affected, those who make virtually no use of the hemiplegic hand.

Though the major abnormality in hemiplegia is loss of voluntary movement patterns, mobility is further impaired by the fact that the limbs are spastic. Spasticity is manifest in increased resistance to passive movement, the clasp knife phenomena; increased stretch reflexes, and increased biceps, triceps, supinator, knee-, and ankle-jerks on the affected side. The plantar response on the affected side is almost always extensor. A high proportion of patients with hemiplegia show associated disabilities. Athetosis, a slow writhing movement of the distal parts of the limb, most commonly the hand, occurs in more than $60 \%$ of cases, much more often than is seen in adults after cerebrovascular accidents. It is best seen when the child tries to reach with the affected hand, when involuntary abduction and extension of the digits and the wrist may be seen. Choreoid movements occur less frequently and almost exclusively in patients in whom hemiplegia is acquired (Gowers, 1876). Recent studies of athetosis have suggested that it may be explained in terms of lack of inhibition of competing grasp and avoiding reflexes (Twitchell, 1958; Rushworth and Denny-Brown, 1959; Denny-Brown, 1960).
Sensory loss of 'cortical type' may be demonstrated in between one-quarter and one-half of patients who suffer from hemiplegia. Patients show impairment of kinaesthetic and two-point discrimination, and often some loss of awareness of positional change in the limbs, though the appreciation of light touch, pin prick, and temperature is usually normal. Sensory loss of this type tends to occur more commonly in patients with acquired hemiplegia than in those with congenital hemiplegia. It is associated with homonymous defects of the homolateral visual field in a significant proportion of cases (Tizard, Paine, and Crothers, 1954; Mitchell, 1961b; Bax, 1962).

Vasomotor disturbances also occur in a high proportion of patients. Commonly the affected limbs are colder than the normal limbs and they become relatively much colder when exposed to low temperature, so that distal cyanosis, sometimes accompanied by oedema, may occur. The motor disability of the hand in some patients may be much increased in cold weather, a fact to which little attention has been paid (Ingram, 1964a).

Dwarfing of the limbs also occurs, more severely in patients with marked paresis than in those in whom the paresis is mild, but not necessarily proportional to the severity of motor involvement (Brissaud, 1896; Holt, 1965) (see Fig. 8.)

The extent to which the child uses the affected hand depends not only upon the degree of motor involvement and the extent to which sensation is impaired, but also upon whether higher level disturbances of function are present. The same neglect of the hemiplegic limbs is found in some adult patients with parietal lobe lesions, and there is evidence that body image may be very disturbed. Gross neglect of the affected limbs and dyspraxia occur more frequently in acquired hemiplegia than in congenital hemiplegia and are important causes of disablement (Critchley, 1953; Denny-Brown and Chambers, 1958; Russell, 1960b; Ingram, Jameson, Errington, and Mitchel', 1964; Albitreccia, 1958).

Mental retardation, epilepsy of various types, speech disorders, specific learning difficulties, and behaviour abnormalities occur in a high proportion of patients with hemiplegia and will be discussed later.

\section{Bilateral Hemiplegia}

Bilateral hemiplegia is the term given to tetraparesis which affects the upper limbs more severely than the lower. It amounts to more than the summation of two hemiplegias, since the bulbar musculature which is spared in hemiplegia is invariably more or less severely affected. The great 


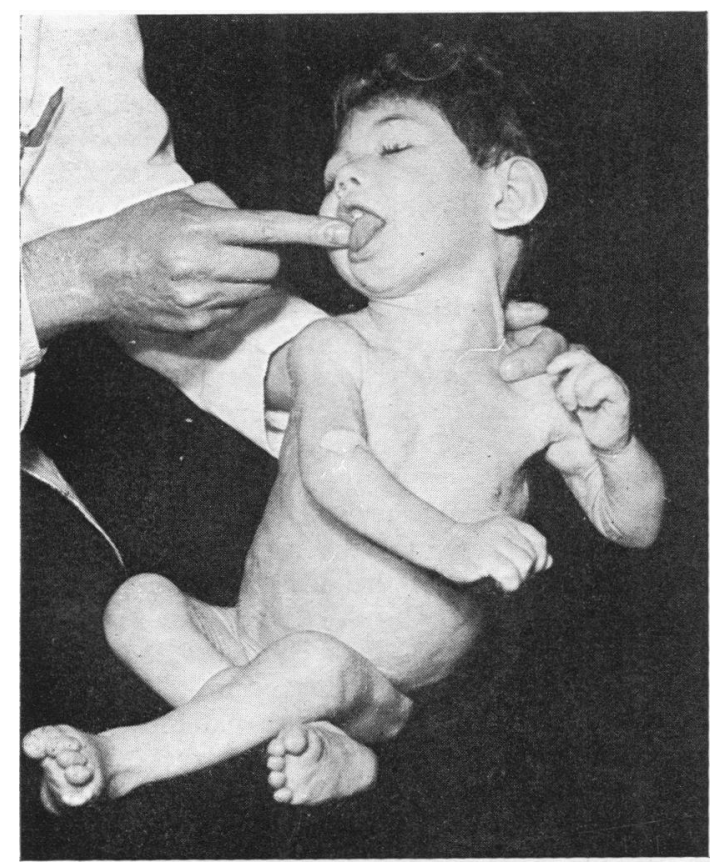

FIG. 5.-The neonatal type of lip reflex with tongue protrusion preceding swallowing in a microcephalic child suffering from bilateral hemiplegia.

majority of patients are severely mentally retarded. Most are also epileptic and the commonest type of epilepsy which young patients show is myoclonic jerks (infantile spasms). Patients with bilateral hemiplegia amount to no more than 4 to $5 \%$ of children with cerebral palsy, but the condition is an important one because of the severity of the physical and mental handicaps (Yannet, 1949; Ingram, 1955a).

Developmental malformations of the brain are usually responsible for congenital bilateral hemiplegia. A veriety of abnormalities has been described including microcephaly, hydroanencephaly, true porencephaly, and schizencephalies (Monakov, 1901, 1926; Minkowski, 1955; Yakovlev and Wadsworth, 1946). These malformations occur more commonly in girls than in boys and are frequently associated with developmental abnormalities of the spine, cardiovascular, alimentary, and genito-urinary systems.

Bilateral hemiplegia is usually of congenital origin. Acquired bilateral hemiplegia after birth is caused by meningitis, acute encephalopathies, and head trauma, and occasionally follows carbon monoxide poisoning or cardiac arrest.

The motor deficit in the limbs in bilateral hemi- plegia is similar to that found in hemiplegia. Usually the severity of involvement is asymmetrical. As in hemiplegia, sensory impairment, vasomotor changes, and dwarfing of the limbs occur.

Involvement of the bulbar musculature leads to feeding difficulties in early infancy, often with nasal escape and choking, sometimes with complicating inhalation of food materials. Later in infancy drooling from the mouth is a prominent feature, and the few children who subsequently develop speech show gross dysarthria (Ingram and Barn, 1961).

The degree of mental defect is commonly severe. As a result behaviour development is retarded, and few patients outgrow the neonatal stage so far as motor achievements and reflexes are concerned. The lip reflex is commonly brisk and when swallowing is stimulated it is characteristically of the neonatal type with tongue protrusion preceding the swallowing (Fig. 5). The Moro reflex, reflex stepping, and the tonic neck reflexes may also easily be obtained (Zappella, 1964; Thomas and Saint Anne Dargassies, 1952; Bobath, 1954; Peiper, 1964).

\section{Diplegia}

Diplegia is nearly always congenital in origin, and at least one-third to one-half of patients in regional surveys are found to have been prematurely born (Hansen, 1960; Mitchell, 1961b). Although abnormalities of pregnancy, labour, and delivery are reported in about two-thirds of patients born at term and in $85 \%$ of patients born prematurely as judged by weight, yet the importance of perinatal injury has probably been overstressed in the past. Mothers of children who suffer from diplegia tend to be less fertile than other women in the community, and there is a high reproductive casualty rate amongst other conceptions through abortion, stillbirth, neonatal death, and postnatal death. In addition, a higher proportion than expected of surviving children are mentally retarded, and have epileptic seizures, or other diseases of the central nervous system (Drillien et al., 1962, 1964). These studies suggest that Freud's (1897) speculations about there being predisposition to suffer from diplegia and other abnormalities of the nervous system in the offspring of some mothers may have been well founded. Diplegia occurs more commonly in twin than in singleton births (Russell, 1961).

Patients who suffer from diplegia are retarded in motor development, and they are relatively more retarded in locomotor development than in manipulative skill, because the neurological involvement in diplegia is greater in the lower limbs than in the upper.

The extent to which linguistic, adaptive, and 


\section{The Neurology of Cerebral Palsy}

social development is retarded depends more upon the degree of any mental subnormality than upon the severity and extent of motor involvement. The majority of diplegics are mentally subnormal and show proportionate slowness in reaching milestones in these spheres of development (Crothers and Paine, 1959; Dunsdon, 1952; Bice and Cruickshank, 1955). The mean intelligence is in the region of 70 . More patients with tetraplegia are severely mentally retarded than are those with paraplegia. The physical findings in diplegia change in a predictable way as the child matures, and various stages in the development of the full clinical picture of diplegia may be defined. These stages merge into each other and are not clearly seen in mildly affected patients, particularly those in whom only the lower limbs are affected. But in severely and moderately severely affected tetraplegics the stages are easier to identify (Ingram, 1955b).

In the first hours or days after delivery a high proportion of the babies show behaviour such as is commonly considered to be caused by perinatal injury to the brain. The child may be unduly lethargic and sleepy, difficult to feed, and limp, or overexcitable, hypertonic, and jittery, or he may have convulsions (Craig, 1938; Prechtl, 1960; Prechtl and Dijkstra, 1960). Once these abnormalities of behaviour in the immediate postnatal period have disappeared, patients with diplegia tend to go through a latent period during which their behaviour is not sufficiently abnormal to make parents consult their doctors. On examination in this phase (which probably lasts between 6 and 12 weeks in moderately severely affected tetraplegic patients) the clinician will find a rather lethargic baby who tends to lie in the semiflexed posture, characteristic of the young newborn, and shows marked poverty of spontaneous movement, especially of the lower limbs. When held in the erect position he cannot support his head and feels floppy or hypotonic. Reflexes characteristic of the newborn period are abnormally easy to elicit, particularly the Moro reflex, stepping reflex, and tonic neck reflexes-further indications of the immaturity of motor development.

This hypotonic stage is gradually succeeded by a 'dystonic' stage in which there is involuntary mass movement and generalized alteration of body tone when the child's position is changed. The child stiffens when held erect or when the head is extended or when pressure is put on the soles of the feet. Mothers commonly notice this stiffening when they handle the child, usually at about the time he is beginning to have some head control in the erect position. When the child is abruptly placed in an erect position, or when his head is allowed to extend suddenly, the lower limbs flex, adduct, and internally rotate at the hips, extend at the knees, and plantar flex at the ankles, so that scissoring occurs. The back is extended and the upper limbs either assume positions similar to those found in hemiplegia, or are adducted, flexed, and internally rotated at the shoulder, extended at the elbow, pronated at the forearms, flexed at the wrists, and the fingers are flexed over the adducted thumbs. These postures can readily be interpreted in terms of the uninhibited action of neck, labyrinthine, and contralateral extensor reflexes described by Sherrington (1906, 1947), Magnus (1926), Peiper (1964), Bobath and Bobath $(1950,1956)$. In this stage the asymmetrical neck reflexes may be shown to be far brisker than they should be, the Moro reflex often persists, the stepping reflex is usually still present, and the grasp reflexes in the hands and feet are likely to be far too easily elicited (Fig. 6). At rest, with the head flexed and with the child in the prone position, muscle tone is usually below normal rather than above, but the tendon jerks, especially in the lower limbs, are increased.

The dystonic stage of diplegia is succeeded by the rigid/spastic stage. Gradually the response of the child being placed in the erect position becomes less abrupt. Hypertonia is not only apparent when the child is placed in the erect position, but is apparent also when he is prone, though it is even more increased when he is placed upright. Initially the hypertonia is of rigid type and the lower limbs tend to be extended at the knees and plantar flexed at the ankles, as in the attacks of stiffening which were earlier characteristic of the dystonic stage (Fig. 7).

In the spastic phase of the rigid/spastic stage, flexor hypertonus is gradually superimposed upon the underlying rigidity, and the biceps, triceps, supinator, knee, and ankle jerks are grossly increased, and stretch reflexes are easily elicited by sudden muscle stretching. The position assumed when erect tends to be similar to that found in bilateral hemiplegia, except that in diplegia the positions are more extreme in the lower limbs than in the upper (Fig. 8).

A few severely affected patients never reach the stage of achieving rigid/spastic cerebral palsy but remain in the dystonic stage. A very small minority of still more severely affected children live for some years in the hypotonic stage. The majority, however, reach the rigid/spastic stage in which there is persistent hypertonus of the limbs in the resting stage, which is exacerbated to a greater or lesser degree by changes of posture. To some extent the outlook for patients suffering from diplegia may be predicted from a study of their early course. Those 

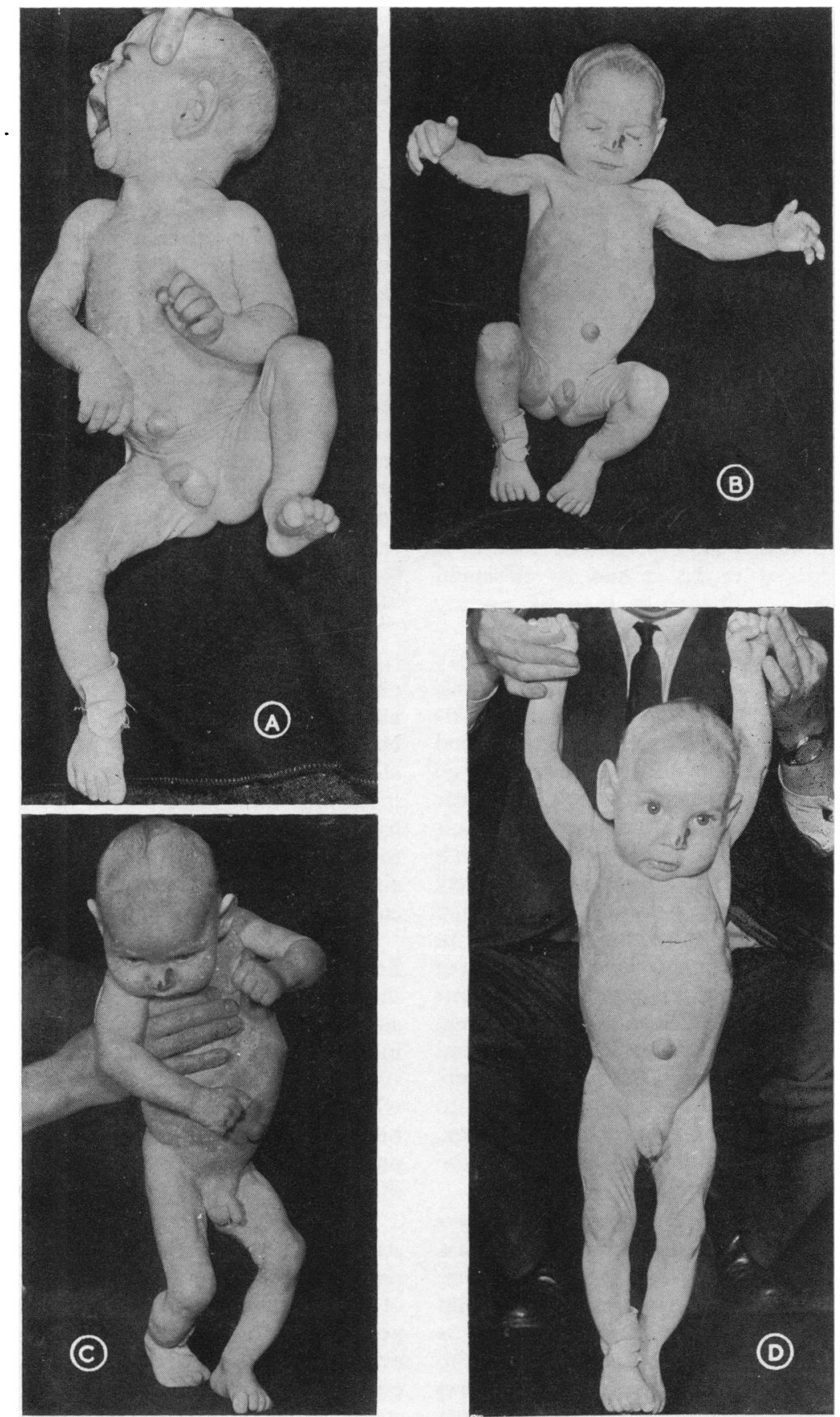


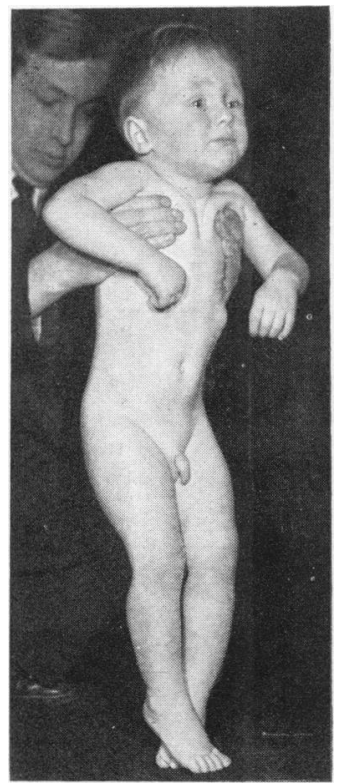

FIG. 7.-Diplegia, a characteristic posture in the early rigid/spastic stage.

who rapidly go through the stages of hypotonia and dystonia and then progress through the predominantly extensor phase or rigid/spastic stage of diplegia have a relatively good prognosis. Patients who are hypotonic for a prolonged period, dystonic for a period of years, and then only gradually merge into the rigid extensor phase of the rigid/spastic stage, have a less good prognosis. Patients who are still in the dystonic stage by the age of 3 rarely walk unsupported in later childhood.

The major disability in diplegia, as in hemiplegia, is loss of voluntary movement patterns, but there are other causes of impaired motor function. Associated movements of athetoid type similar to those found in hemiplegia occur in a minority of patients. In many patients dystonic movements persist into the rigid/spastic phase. Choreoid movements are rare. Contractures tend to occur especially in the equinus positions. Impairment of vasomotor control in the lower limbs occurs in the majority of cases of diplegia. Chilblains are additional complications especially in the winter months.

There is some degree of dwarfing of the pelvis and lower limbs in practically all diplegics, and this is usually roughly proportional to the severity of the paresis. The complications of mental defect, epilepsy, speech disorders, and abnormalities of the eyes, particularly strabismus which occurs so frequently in diplegia, will be discussed later.

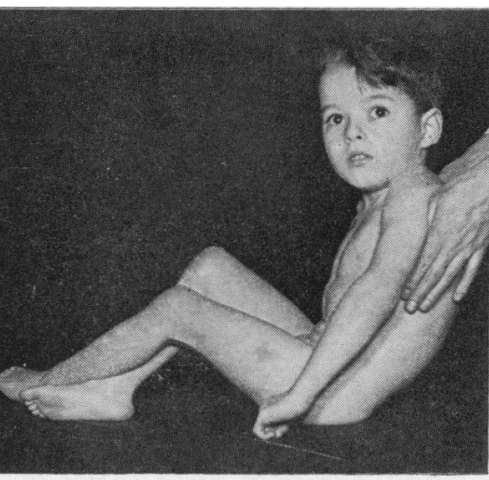

(a)

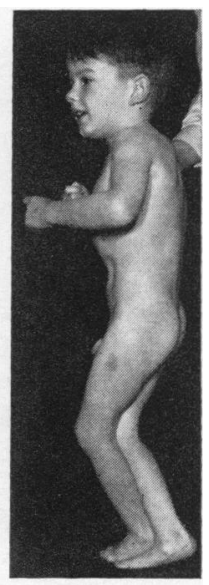

(b)

FIG. $8 a$ and $b$.-Diplegia, flexor hypertonus gradually increases in the rigid/spastic stage. Postures in the supported sitting and supported standing positions in a later stage of rigid/spastic diplegia than is shown in Fig. 7.

\section{Ataxic Cerebral Palsy}

Ataxic cerebral palsy is more often unrecognized than any other type of cerebral palsy, though recent regional surveys have suggested that $5-10 \%$ of cases of cerebral palsy are suffering from ataxia (Skatvedt, 1958; Woods, 1957; Andersen, 1954). The majority of cases are congenital in origin and result from malformations of the cerebellum and its connexions (Norman, 1963). Acquired ataxic cerebral palsy may be caused by meningitis, by septic, acute, disseminated, and toxic encephalopathies, and by trauma.

It is convenient to distinguish between ataxic children who also develop spasticity in the lower limbs as they grow older and those who remain hypotonic (Table II, Ingram, 1963).

In the majority of cases of children with ataxic diplegia or ataxia the birth was normal, but even in the neonatal period many of the children were noted to be lethargic, relatively immobile, and floppy when picked up. Indeed, congenital ataxic cerebral palsy is one of the more frequent and important causes of the 'floppy baby syndrome' (Schutt, 1963; Brandt, 1950; Tizard, 1964). There is retardation of motor development. The babies are slow to hold up their heads, to sit without support (Fig. 9), and, as noted by Schutt (1963), 'the more erect the posture becomes the longer the delay in attaining the subsequent stage of locomotion'. The mean age for walking in his patients was $\mathbf{3 4}$ months. He noted the great fear of standing or walking unsupported that many children had, even when they could walk 
TABLE II

Comparison of Findings in Children with Ataxic Diplegia and Ataxia

\begin{tabular}{|c|c|c|c|c|}
\hline & & & Ataxic Diplegia & Ataxia \\
\hline $\begin{array}{l}\text { Gait } \ldots \\
\text { Muscle tone } \\
\text { Tendon jerks } \\
\text { Plantar responses } \\
\text { Later contractures } \\
\text { Epilepsy }\end{array}$ & $\begin{array}{l}\cdots \\
\cdots \\
\cdots \\
\cdots \\
\cdots\end{array}$ & $\begin{array}{l}\cdots \\
\cdots \\
\cdots \\
\cdots \\
\cdots\end{array}$ & $\begin{array}{l}\text { Less broad-based; on the toes } \\
\text { Spastic, especially in lower limbs } \\
\text { Always exaggerated especially in lower limbs } \\
\uparrow \uparrow \uparrow \\
\text { Frequent } \\
\text { Quite frequent }\end{array}$ & $\begin{array}{l}\text { Very broad-based; flat-footed } \\
\text { Hypotonic } \\
\text { Usually sluggish } \\
\text { Usually } \downarrow \downarrow \downarrow \\
\text { Never } \\
\text { Infrequent }\end{array}$ \\
\hline
\end{tabular}

quite confidently with a little support. As noted in Table II patients with only ataxia tend to have a broad-based, flat-footed gait (Fig. 10), whereas in those with ataxic diplegia this gait is modified by the diplegia so that they tend to walk on their toes and on a less broad base (Fig. 11).

Hypotonia is maximal in the neonatal period, the muscle tone gradually increasing with age, though never reaching normal. The limbs show weakness, incoordination of voluntary movement, dysdiadochokinesis, intention tremor, and titubation which may be apparent even in the sitting position.

It is unusual to find either nystagmus or a positive Romberg sign in congenital ataxia or ataxic diplegia. The extent to which linguistic, adaptive, and social behaviour is retarded in development depends more upon the degree of the mental subnormality which is commonly present than upon the ataxic cerebral palsy itself. Ataxic diplegia is the form of cerebral palsy most often associated with hydrocephalus.

\section{Dyskinesia}

The involuntary movements and involuntary changes in muscle tone, which are the major motor disabilities in dyskinesia, are of various types. By dystonia is understood a slow writhing movement of the proximal part of the limbs and trunk, which commonly results in the affected part of the body assuming a position like that found in opisthotonus. Athetosis is a slow writhing movement which affects the distal part of the limbs and is most evident in the fingers and wrists in the upper limbs. It is best seen when patients reach for an object, for instead of grasping it with accurate finger flexion and opposition of the thumb and index finger, an involuntary writhing movement occurs which consists of extension and abduction of the digits and extension of the wrists. Choreoid movements are rapid movements of the proximal parts of the limbs which involve agonists and antagonists. Like dystonic movements they usually tend to use positions similar to those found in opisthotonus. By tremor is understood a recurring involuntary movement which usually has a rhythm. Tremor is classically seen in Parkinson's disease in the adult but is less common than dystonic, choreoid, and athethoid movements in cerebral palsy affecting children. By tension is understood the sudden

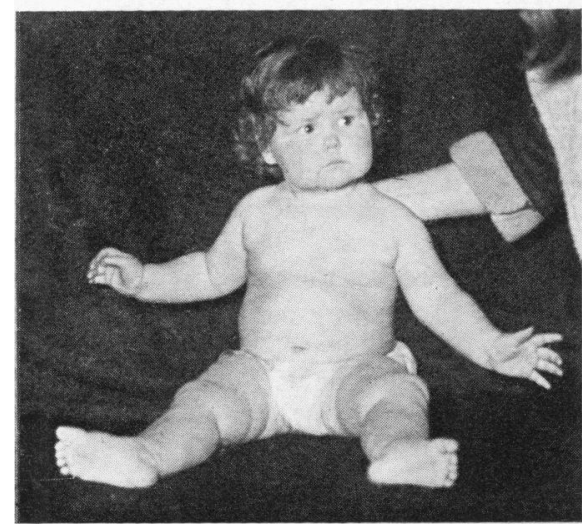

(a)

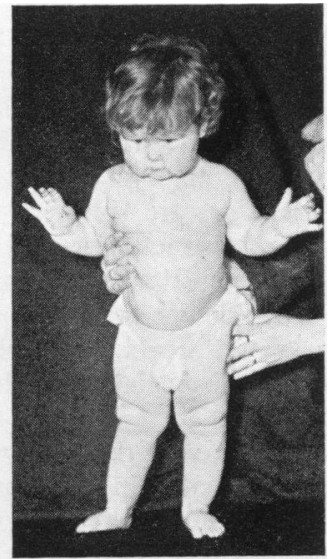

(b)

Fig. 9.-(a) Inability of a child aged 14 months with ataxia to sit without support. The excessive 'balancing' movements of the upper limbs are well shown.

(b) The same child standing supported. 


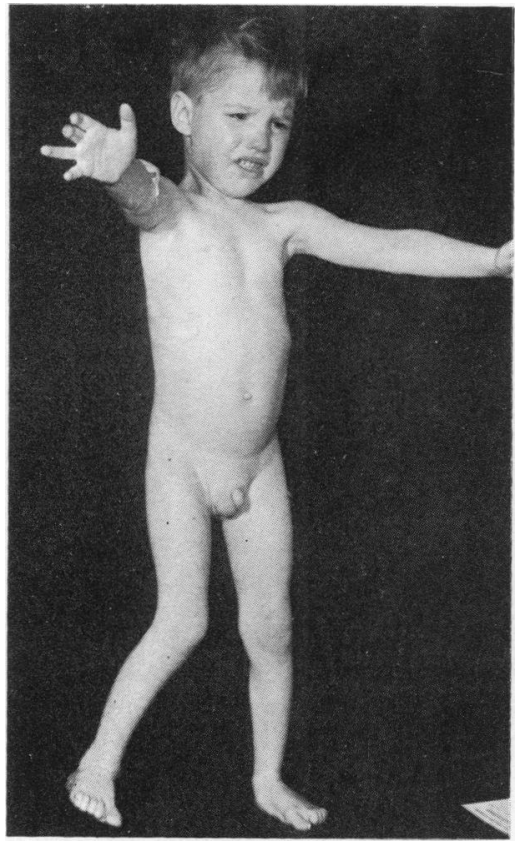

FIG. 10.-Characteristic broad-based, flat-footed gait in severe ataxia.

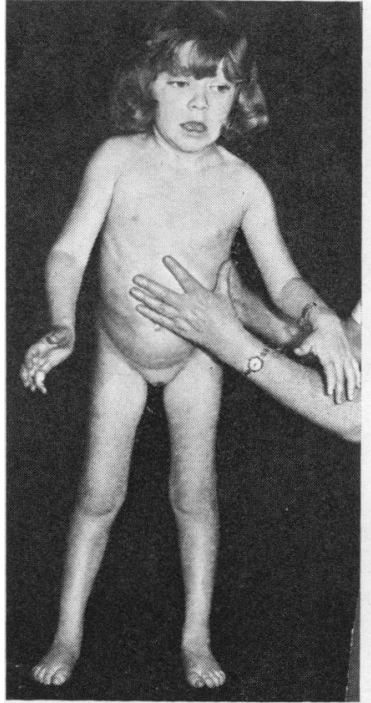

(a)

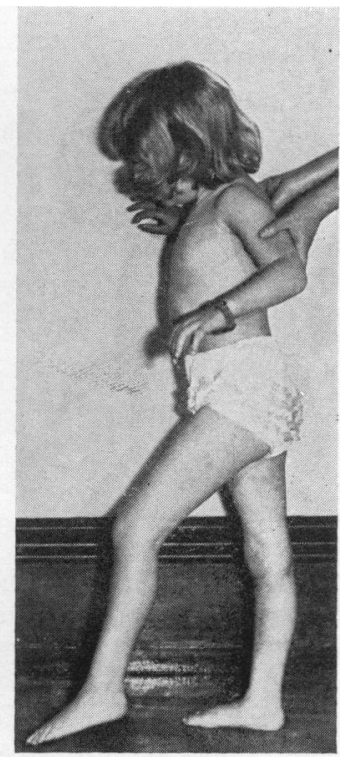

(b)
FIG. $11 a$ and $b .-T e n d e n c y$ to rise on to the toes when walking in ataxic diplegia. The gait is broad-based because the diplegic component is not marked.

with most if not all everyday activities and cannot feed, dress, or toilet themselves. This classification is similar to that suggested by Mitchell (1961a).

Dyskinesia is almost always the result of perinatal injury to the brain, from causes such as perinatal hypoxia, or hyperbilirubinaemia leading to kernikterus, so that in a high proportion of cases there is a history of abnormal behaviour in the neonatal period (de Lange, 1924). After the acute symptoms and signs of 'birth injury' or kernikterus have resolved, these patients pass through a latent stage in which their behaviour does not appear to be grossly abnormal, though a rather high proportion have feeding difficulties (more than two-thirds give a history of regurgitation, difficulty in swallowing, or vomiting in the early months of infancy). A few, particularly those who have suffered from kernikterus, have alterations of sleep rhythm which parents often have good cause to remember even years later.

On examination at this stage of latent or hypotonic dyskinesia, the most striking findings are the general retardation of the neuromuscular development, the poverty of movement, and the generalized hypotonia. Reflexes which are normally present only in the newborn baby persist, and even at the age of 3 or 4 months may be elicited with ease (Fig. 12). The stepping reflex and Moro reflex are commonly very 


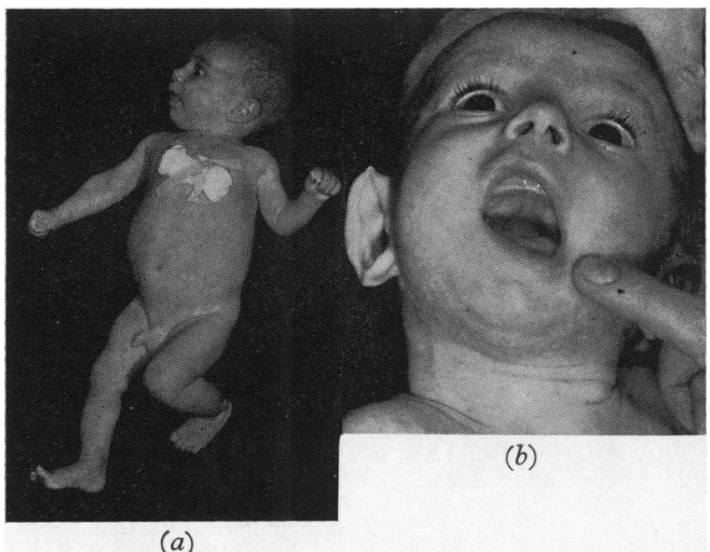

FIG. 12.-(a) The asymmetrical neck reflex in a baby suffering from early dyskinetic cerebral palsy following kernikterus. The staring downcast eyes are characteristic.

(b) The lip reflex in the same baby.

easy to elicit, but it is the persistence and dominance of the asymmetrical neck reflex which is most characteristic of dyskinetic cerebral palsy. In kernikteric patients the inability to look upwards is manifest at an early age, and even in the absence of other signs suggestive of cerebral palsy should put the clinician on his guard and make him suspect brain damage (Evans and Polani, 1950; Greenwald and Messer, 1927; Plum, 1965).

The duration of the latent or hypotonic stage is very variable and in severely affected babies it may persist for a year or more. The hypotonic stage is succeeded by a stage in which involuntary movement of the trunk and limbs occurs when the baby attempts voluntary movements and when it is handled. There is a tendency to mass involuntary movement. This may appear gradually so that the parents can hardly date its onset, or it may come on suddenly, very often in the presence of a febrile illness. In this stage of mass involuntary movement, which does not occur in all patients who suffer from dyskinesia, there is a tendency for head retraction, back arching, and opisthotonus. For example, a baby aged 5 or 6 months may try to reach for an object, and as he does so he involuntarily stiffens and shows hyperextension of the neck and trunk, adduction, internal rotation and flexion of the shoulders, extension of the elbows, pronation of the forearms, semiflexion of the wrists, and flexion of the fingers over the adducted thumbs. The lower limbs adduct and internally rotate at the hip, extend at the knee, and the feet plantar flex. There is scissoring of the lower limbs. The same type of mass movement occurs when the child is handled,

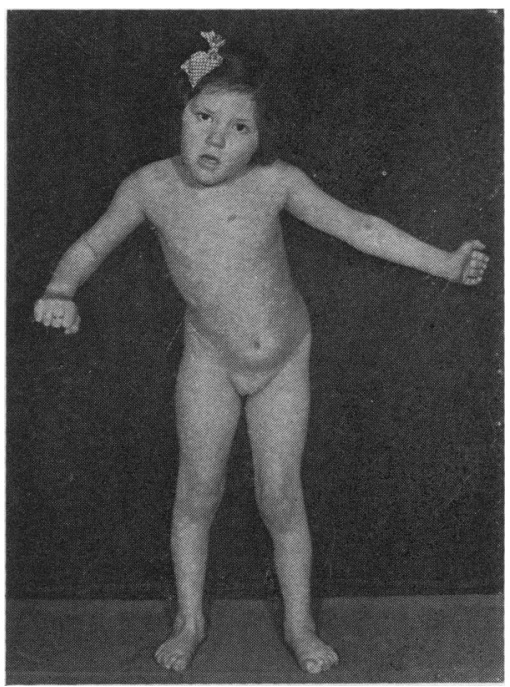

FIG. 13.-'Overflow' of involuntary movement affecting both upper limbs and face when she tries to stand without support.

especially if he is placed in the erect position or his head is allowed to extend suddenly as when he is being bathed. The positions of the trunk and limbs which are assumed during this stage are thus very similar to those found in diplegic children during their 'dystonic stage'. As in diplegia, the duration of the dystonic stage or stage of mass movements is variable. Severely affected patients may never outgrow it, but in the majority it will last for only a few weeks and then gradually merge into a stage in which involuntary movements become progressively more limited in their extent and distribution, and occur rather less readily.

It is in this stage of dyskinesia in which discrete involuntary movements are apparent, that the various types of involuntary movement can be recognized, and the distribution in which they occur may be perceived. Thus instead of showing a position equivalent to generalized opisthotonus whenever he attempts to move, the child who enters the stage of more discrete involuntary movements will show some tendency to extensor hypertonus and show back arching. But it is only the upper limb that he is trying to move that will assume the full opisthotonic posture. The amount of overflow of involuntary movement from one part of the body to the other during this stage is variable. Those patients with severe choreoid movements and dystonia show a tendency to 'overflow', so that any attempted movement of a hand will be accompanied by involuntary movements not only in the other hand but in the face, trunk, and lower limbs (Fig. 13). 
As in diplegia, various infantile reflexes persist in patients with dyskinesia. The stepping reflex is often completely uninhibited and uncontrolled, and may appear as 'cycling movements' of the legs, especially in the erect position in severely affected patients. The asymmetrical tonic neck reflexes (Fig. 14) may be so marked that the child cannot turn her head without completely disorganizing her whole balance, as her limbs involuntarily alter position, and the Moro reflex may also be elicited by a wide variety of slight movements on fairly quiet sound stimuli.

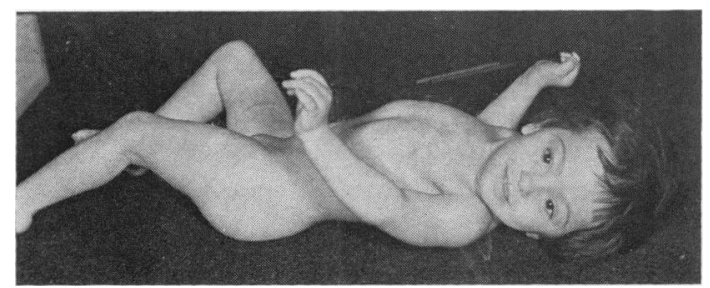

FIG. 14.-The asymmetrical neck reflex in an older child suffering from dyskinesia.

At absolute rest in the prone position with head flexed, the patients with dyskinesia are usually hypotonic, though as noted by Plum (1965) a proportion, particularly those who have suffered from perinatal hypoxia, show some spasticity. In dyskinesia, however, more than in any other type of cerebral palsy, it is by prolonged observation of the child in everyday activities such as walking, talking, dressing, and undressing, feeding, or attempting to play that the clinician diagnoses the nature of his illness and assesses its distribution.

Fewer patients who suffer from dyskinesia are seriously mentally subnormal than are patients who suffer from other types of cerebral palsy. Fewer have epilepsy. On the other hand, a relatively high proportion have high tone or even nearly total hearing loss. Because of the combination of involuntary movements of the lips, tongue, and palate, and hearing loss, a high proportion have severe speech defects, the more damaging since these patients tend to be intelligent (Asher, 1952; Fisch, 1955; Crothers and Paine, 1959).

\section{Associated Disabilities in Patients Who Suffer from Cerebral Palsy}

If the motor deficit in cerebral palsy were the only causes of handicap, a high proportion of patients would be leading almost normal lives. It is because of the associated disabilities, in particular intellectual impairment, epilepsy, speech defects, disorders of vision and hearing, and specific educational and behavioural abnormalities, that the majority cannot take their place in normal society (Crothers and Paine, 1959; Henderson, 1961; Ingram, 1964a).

Intellectual impairment. The majority of patients with cerebral palsy are of subnormal intelligence (Dunsdon, 1952; Floyer, 1955; Illingworth, 1958; Cockburn, 1961). In most series approximately one-third of patients are found to be of average or superior intelligence and the remainder are mentally subnormal. In a recent study in Edinburgh it was found that approximately $22 \%$ of patients had IQs of less than 55 , and $24 \%$ had IQs between 70 and 84 . Children with bilateral hemiplegia, or diplegia with tetraplegic involvement, were less intelligent than those with hemiplegia, diplegia with only paraplegic involvement, or dyskinesia. Within the individual categories of cerebral palsy, children with extensive or severe physical defects tended to be less intelligent than those whose limb involvement was less marked.

Difficulties in learning to read and write occur frequently in patients with cerebral palsy. Those with retarded speech development are likely to have difficulties in breaking down words correctly into their component sounds when trying to write them, and in synthesizing the parts they have correctly read and sounded when reading. Others, particularly those with ataxia, are likely to have great difficulties in recognizing, orienting, and placing in order patterns such as letter shapes, and in reproducing them. These difficulties, which may be termed 'visuo-spatial', have been increasingly recognized by teachers of cerebral palsied children (Taylor, 1959; Berko, 1954; Lord, 1937; Nelson, 1962; Nielsen, 1962; Prechtl, 1962; Wedell, 1960; Ingram, 1960).

Speech defects. The percentages of children considered to suffer from defective speech in different series will vary according to the criteria of defective speech adopted by the workers concerned. When moderate intelligibility is required, about $50 \%$ of patients in regional surveys have significant speech defects (Ingram, 1955a; Hansen, 1960). Contrary to many published opinions, true dysphasia is rare in these children (Guttmann, 1942). True dysphasia may occur in children who suffer from injury to the dominant hemisphere after the age of about 3 years, but if the injury is sustained much before this then the effect on speech is likely to be either to retard subsequent development or to produce a mixed picture of loss of acquired speech and slowness of development. 
In a series of patients studied in Edinburgh it was found that the commonest disorder of speech in hemiplegic children was simple retardation of speech development. The acquisition of speech sounds, words, and phrases was slowed. The next most frequent type of abnormality was speech dysrhythmia. Specific language disability occurred in approximately $12 \%$ of hemiplegic patients.

The most important cause of speech abnormality in diplegic patients was retarded speech development, and the retardation of speech development tended to be proportional to the degree of mental handicap and to the extent of the paresis. Dysarthria was commoner amongst diplegic than amongst hemiplegic children; it occurred more often in tetraplegia than in triplegia or paraplegia; it was invariably accompanied by impairment of voluntary movements of the lips, tongue, or palate, and in most of the severely affected patients all three organs were involved. A high proportion of children with severe dysarthria or no speech development had a history of feeding difficulty or drooling in infancy. Many of these were found to have lip and sucking reflexes that were remarkably easy to elicit.

There is a characteristic form of dysarthria in diplegic children, which consists of slowing of utterances and monotony of intonation and stress patterns. There is often slight or moderate nasal escape because of palatal paresis, and hypernasality results. Speech sounds are laboured and vowels are better used than consonants. Dysarthria occurred as the only abnormality of speech in about $20 \%$ of the diplegic patients and in association with other speech disorders in a further $24 \%$ (Ingram and Barn, 1961).

Most children with ataxic cerebral palsy have defective speech. As with other forms of cerebral palsy, the commonest disorder is simple retardation of speech development. This may occur alone, but is commoner in association with dysarthria and other abnormalities including dysrhythmia of a characteristic type. The retardation of speech development tends to be proportional to the degree of mental impairment, but a few patients who suffer from ataxia show severity of retarded speech development which is quite disproportionate to their mental subnormality. Thus children who appear to be of average intelligence so far as their general behaviour development is concerned may have little or no speech even at the age of 5 or 6 years.

The characteristic scanning speech found in adult patients with ataxia is also found in children with ataxic cerebral palsy, and in addition incoordination of tongue, lip, and palatal movements results in dysarthria. The consistency with which word sounds are either omitted or substituted is less constant in the dysarthria which complicates ataxic cerebral palsy than it is in diplegia. Dysrhythmia and associated abnormalities of intonation and stress which are very difficult to analyse occur in a high proportion of ataxic children.

The characteristic facile talkativeness of many hydrocephalics is well known. Their readiness to speak may give a false impression of intelligence, which is only dispelled when the content of what they say is analysed and found to consist of 'parrottings' of adult speech and repetitive jargon (Ingram and Naughton, 1962).

Only a small proportion of dyskinetic children speak normally. The majority have complex speech defects due to a number of different causes. In the same Edinburgh series $78 \%$ of 67 children who suffered from dyskinesia were found to have speech defects or virtual absence of speech due to multiple causes. Only in $22 \%$ were the disorders thought to be entirely the result of dysarthria, retardation of speech development, or dysrhythmia. Retardation of speech development attributable to mental subnormality was a less important cause than in other categories of cerebral palsy, but retardation of speech due to impairment of hearing was much more frequent than in the other categories.

Behaviour abnormalities. Since Strauss and Lehtinen (1947) described patterns of behaviour which they considered were directly attributable to the effects of brain damage, there has been increasing interest in the behaviour abnormalities that are found in cerebral palsy. Michell (1963) has described hyperkinesis, short attention span, and distractibility, lability of mood, antisocial behaviour manifest as lying, stealing, truancy, offences of cruelty, difficulties in abstract thought, and attacks of extreme anxiety with panic, as characteristic of the brain-damaged child. It is, however, difficult to assign abnormalities of behaviour such as these to either 'organic' causes or to the consequential 'psychological stresses' (Bice, 1952; Wortis and Cooper, 1957; Kelman, 1964; Ingram, 1963) (Table III).

Distractibility and short attention span are as often as not secondary manifestations of mental defect, but the syndrome of hyperkinetic behaviour which occurs in a proportion of children who have suffered from localized hemisphere damage affecting one or both temporal lobes is characteristic. They show an intense preoccupation with their immediate surroundings, marked restlessness, and an almost compulsive desire to explore everything in the 
TABLE III

Relationship of Various Clinical Syndromes (excluding Cerebral Palsy, Epilepsy, and Mental Defect) to Organic Brain Abnormality

\begin{tabular}{l|l|l}
\hline $\begin{array}{c}\text { Defined Clinical Syndrome with } \\
\text { Constant Evidence of Brain } \\
\text { Abnormality }\end{array}$ & $\begin{array}{c}\text { Defined Clinical Syndromes with } \\
\text { Inconstant Evidence of Brain } \\
\text { Abnormality }\end{array}$ & $\begin{array}{l}\text { Symptoms in Which Brain Abnormality } \\
\text { May be an Inconstant Direct or } \\
\text { Indirect Contributory Cause }\end{array}$ \\
\hline $\begin{array}{c}\text { Examples } \\
\text { Choreiform syndrome } \\
\text { Minor cerebral palsy }\end{array}$ & $\begin{array}{c}\text { Examples } \\
\text { Specific retardation of speech } \\
\text { development } \\
\text { Specific developmental dyslexia and } \\
\text { dysgraphia } \\
\text { Sypecific 'clumsiness' }\end{array}$ & $\begin{array}{l}\text { Examples } \\
\text { Distractability } \\
\text { Variability of behaviour } \\
\text { Impulsiveness } \\
\text { Irritability }\end{array}$ \\
& & Anxiety \\
& Emotional immaturity \\
\hline
\end{tabular}

vicinity by touching it or putting it to the mouth. Often there is an almost complete lack of insight or consideration for other people, and an inability to accept the least frustration, so that any checking of activities may result in the child attacking whoever tries to stop him from gratifying his momentary whim. A similar type of behaviour may be produced in monkeys by making discrete lesions in one or other temporal lobe in the region of the hypocampus (Klüver and Bucy, 1939; Ounsted, 1955; Ingram, 1956). It is characteristic of this syndrome that the administration of phenobarbitone to patients exacerbates it, while administration of antiepileptic drugs such as primidome or sulthiame may alleviate it. As affected patients grow older their hyperactivity diminishes. Overactive behaviour of the type described by Ounsted is most commonly found amongst cerebral palsy patients who suffer from acquired hemiplegia and ataxic diplegia.

Epilepsy. In most regional studies of cerebral palsy epilepsy has been present in $20-50 \%$ of patients, though the reported incidence of recurrent seizures has varied considerably (Asher and Schonell, 1950; Perlstein and Hood, 1954; Perlstein, Gibbs, and Gibbs, 1953; Skatvedt, 1958; Hansen, 1960). In a recent study, 23 of 57 children suffering from hemiplegia and followed for an average of 4.5 years had epilepsy: poor control of seizures was associated with lower intelligence and lower speech and behaviour levels than were found in seizure-free patients (Jabbour and Lundervold, 1963).

The commonest form of seizure encountered in cerebral palsy is grand mal, and this is most frequently found in those with hemiplegia, bilateral hemiplegia, and diplegia. Children with ataxic cerebral palsy and dyskinesia less often have grand mal seizures. Focal seizures occur more commonly in those with hemiplegia, bilateral hemiplegia, and ataxic diplegia than in those with diplegia or dyskinesia. Myoclonic attacks (infantile spasms) occur most commonly in children with severe mental defect, especially if their brain anomalies are attributable to severe developmental malformations. True petit mal is relatively rare in cerebral palsy, though it is often diagnosed (Woods, 1957; Skatvedt, 1958).

A much higher percentage of patients who have clinical seizures have abnormal EEGs than do those without seizures (Perlstein, Gibbs and Gibbs, 1955; Woods, 1965; Gibbs, Gibbs, Perlstein, and Rich, 1963). The latter authors noted that there was a high correlation between the presence of multiple focuses of spike activity and educability. Their extensive study on 2,124 cases of cerebral palsy suggests that the value of the EEG in cerebral palsy has not yet been fully appreciated.

Seizures in patients with cerebral palsy are difficult to control, and in particular focal seizures in hemiplegia seem to be resistant to treatment with anti-epileptic drugs (Crothers and Paine, 1959; Fukuyama, Arima, Nagahata, and Okada, 1963), as are also myoclonic seizures (Jeavons and Bower, 1964; Pederson, 1964; Gastaut, Poirer, Payan, Salamon, Toga, and Vigouroux, 1960).

Visual disorders. Visual acuity is difficult to test in young children, and it is only recently that attempts to test vision in children under 1 year have proved reliable (Sheridan, 1965). This may account for the fact that the incidence of visual disorders reported in different series of patients varies so greatly. The most comprehensive study is that of Douglas, who studied 168 patients in the survey conducted in Dundee by Henderson (1961), though even his series is selected, so that the conclusions that can be drawn from it must be limited. Douglas found that $35 \%$ of the patients 
suffered from strabismus, $13 \%$ from nystagmus, $4 \%$ from colobomata, $10 \%$ from optic atrophy, and $1 \%$ from congenital cataract.

If this survey had been carried out a few years earlier, cases of retrolental fibroplasia would no doubt also have been found, particularly in prematurely born patients who suffered from diplegia (Ingram and Kerr, 1954).

Visual field defects are practically confined to patients with hemiplegia, bilateral hemiplegia, and ataxic diplegia, and are found in $10-25 \%$ of cases. They are difficult to diagnose before the patients can co-operate fully, particularly since good compensation can be achieved by the age of 2 or 3 , even in those with complete hemianopia.

Further studies of eye movements in the newborn and of strabismus in cerebral palsy have recently been presented by Douglas (1963), Smith (1963), and Griffiths and Smith (1963). It is apparent that strabismus is a frequent and important complication of cerebral palsy, but it is debatable how far paresis of ocular nerves is responsible.

Hearing impairment. Fisch (1957) found that $25 \%$ of patients with cerebral palsy who attended school had some hearing impairment. In Dundee $23 \%$ of 70 co-operative cerebral-palsied patients without severe mental impairment were found to be hard of hearing (Mowat, 1961). In contrast, 5\% of cerebral-palsied children were found by MacGregor, Pirrie, and Shaddick (1957), to suffer from hearing impairment, $7 \%$ by Woods (1957), and $8 \%$ by Ingram (1955a). These varied figures may well be attributable to different techniques of assessment as well as to the selection of cases.

All appear to agree, however, that hearing loss occurs more frequently in those with dyskinesia than it does in other forms of cerebral palsy, and that children with bilateral hemiplegia and severe diplegia more often suffer from hearing loss than do those with ataxia and hemiplegia (Ingram, 1964a).

\section{Recent Studies of Changes of Muscle Tone in Cerebral Palsy}

It is not proposed to discuss the underlying neurophysiology of cerebral palsy, but recent work on the origin of muscular hypertonus and its abolition by the injection of local anaesthetics and alcohol into nerves and nerve endings must be mentioned.

Resting muscle tone is changed by many influences, such as the age of the child, his alertness, his emotional state, and his temperature. Tone is influenced by these factors through the muscle spindles and their neural connexions with the spinal cord-the so-called $\gamma$ system. Efferent impulses from higher nervous centres acting through the $\gamma$ system cause changes in the length of muscle spindles, and hence increase or decrease the afferent discharges to the spinal cord. The $\gamma$ system appears to operate as a closed-loop servo-mechanism controlling the length and tension of muscle, both in voluntary movement and the involuntary activity of muscles, which serves to maintain posture (Fig. 15).

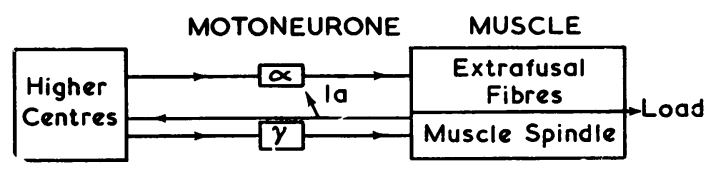

FIG. 15.-Simplified diagram of the $a$ and $\gamma$ pathways for controlling skeletal muscle (from Mattherws, 1964).

A continual state of equilibrium between load and muscle length and tension can be envisagedmuscle activity being reflexly stimulated through tendon endings and muscle spindles, whenever the load stretches a muscle beyond certain limits. Thus the activity of the $\gamma$ system can set the level at which the stretch reflex operates. In states in which the $\gamma$ system is uninhibited the stretch reflex is active; when the clinician moves a muscle in this state passively he is likely to consider it to be hypertonic or rigid or spastic. Whereas if the $\gamma$ system is relatively inactive he will appreciate that resistance to passive movement is less than he had expected, and will consider the muscle to be 'hypotonic'. It appears that the effect of local anaesthetic and of alcohol in reducing rigidity and spasticity in experimental animals is a result of a relatively specific action of these substances on $\gamma$ nerve endings (Walshe, 1923, 1924; Matthews and Rushworth, 1957; Rushworth, 1959, 1960, 1962).

It is tempting to speculate about the role of the $\gamma$ system in altering muscle tone in children with cerebral palsy. Infiltrations of alcohol into nerves, motor points, and other parts of muscles have been carried out in children with spasticity attributable to cerebral lesions. The success of the procedures has varied greatly, but when successful they have resulted in a marked reduction of muscle hypertonia (Sachs and Hausman, 1926) and of the stretch reflex. This finding not only suggests a new approach to the treatment of spasticity and contracture palsy, but provides promising avenues for future research, which may lead to better understanding of disorders of muscle tone and more rational treatment of many patients with cerebral palsy (Tardieu, Tardieu, Hariga, Gagnard, and Velin, 1964; Tardieu and Hariga, 1964). 
I would like to thank Professor and Mrs. Fog for their permission to reproduce Fig. 1b; Dr. Gordon Stark for the photographs in Fig. 4; Dr. Aron Holzel for the information he supplied; the Editors of Developmental Medicine and Child Neurology and Acta Paediatrica Scandinavica for permission to reproduce material; Messrs. E. and S. Livingstone for permission to use material from my book Paediatric Aspects of Cerebral Palsy; and my colleagues Professor J. O. Forfar, Dr. J. W. Farquhar, and Dr. C. M. Drillien for their helpful comments.

\section{REFERENCES}

Albitreccia, S. I. (1958). Recognition and treatment of disturbances of the body image. Cerebr. Palsy Bull., 1(4), 12.

Andersen, B. (1954). Cerebral palsy. F. Oslo Cy Hosp., 4, 65.

Asher, P. (1952). A study of 63 cases of athetosis with special reference to hearing defects. Arch. Dis. Childh., 27, 475.

, and Schonell, F. E. (1950). A survey of 400 cases of cerebral palsy in childhood. ibid., 25, 360.

Balf, C. L., and Ingram T. T. S. (1955). Problems in the classification of cerebral palsy in childhood. Brit. med. F., 2, 163.

Batten, F. E. (1903). Congenital cerebellar ataxia. Clin. F., 22, 81. (1905). Ataxia in childhood. Brain, 28, 484.

- (1907). Two cases of ataxia in children. ibid., 30, 144.

Bax, M. (1962). Late sequelae of acute hemiplegia in childhood. Little Club Clin. develop. Med., 6, 20.

, and Mitchell, R. (1962). Acute hemiplegia in childhood. ibid., 6.

Bergès, J., and Lézine, I. (1965). The imitation of gestures. ibid., 18.

Berko, M. J. (1954). Some factors in the perceptual deviation of cerebral palsied children. Cerebral Palsy Rev., 15, 3.

Bice, H. V. (1952). Group Counseling with Mothers of the Cerebral Palsied. National Society for Cripplied Children and Adults, Chicago.

—, and Cruickshank, W. M. (1955). The evaluation of intelligence. In Cerebral Palsy, ed. W. M. Cruickshank and G. M. Raus, p. 87. Syracuse University Press, Syracuse (N.Y.).

Bobath, B. (1954). A study of abnormal postural reflex activity in patients with lesions of the central nervous system. Physiotherapy, 40, 259 and 295.

Bobath, K., and Bobath, B. (1950). Spastic paralysis: treatment of by the use of reflex inhibition. Brit. F. phys. Med., 13, 121. , and - (1956). The diagnosis of cerebral palsy in infancy. Arch. Dis. Childh., 31, 408.

- and - (1962). An analysis of the development of standing and walking patterns in patients with cerebral palsy. Physiotherapy, 48, 44

Brandt, S. (1950). Werdnig-Hoffmann's Infantile Progressive Muscular Atrophy. Munksgaard, Copenhagen.

(1962). Causes and pathogenic mechanisms of acute hemiplegia in childhood. Little Club Clin. develop. Med., 6, 7.

Braudo, M. (1956). Thrombosis of internal carotid artery in childhood after injuries in region of soft palate. Brit. med. $\mathcal{F}$., 1,665 .

Brissaud, É. (1896). Atrophies musculaires tardives consécutives à la paralysie infantile. Presse méd., 145.

Byers, R. K. (1941). Evolution of hemiplegias in infancy. Amer. f. Dis. Child., 61, 915.

- (1942). Discussion on athetosis and paralysis agitans. Res. Publ. Ass, nerv. ment. Dis., 21, 487.

- and Hass, G. M. (1933). Thrombosis of the dural venous sinuses in infancy and in childhood. Amer. F. Dis. Child., 45, 1161.

Carlson, E. R. (1942). Treatment of athetosis by retraining. Res. Publ. Ass. nerv. ment. Dis., 21, 534.

Cockburn, J. M. (1961). Psychological and educational aspects. In Cerebral Palsy in Childhood and Adolescence, ed. J. L. Henderson, p. 281. Livingstone, Edinburgh.

Courville, C. B. (1953). Contributions to the Study of Cerebral Anoxia. San Lucas Press, Los Angeles.

(1954). Cerebral Palsy. San Lucas Press, Los Angeles.

Craig, W. S. (1938). Intracranial haemorrhage in the new-born. A study of diagnosis and differential diagnosis based upon pathological and clinical findings in 126 cases. Arch. Dis. Childh., 13, 89.

Critchley, M. (1953). The Parietal Lobes. Amold, London.
Crothers, B. (1921). Lesions of the corpus striatum in childhood, with report of clinical cases. Amer. F. Dis. Child., 22, 145. , and Paine, R. S. (1959). The Natural History of Cerebral Palsy. Harvard Univ. Press, Cambridge (Mass.); Oxford University Press, London.

Denhoff, E., and Holden, R. H. (1951). The significance of delayed development in the diagnosis of cerebral palsy. F. Pediat., 38, 452.

Denny-Brown, D. E. (1960). Motor mechanisms.-Introduction: the general principles of motor integration. In Handbook of Physiology Section, Section 1, Neurophysiology, vol. 2, p. 781. Amer. Physiol. Soc., Washington.

—, and Chambers, R. A. (1958). The parietal lobe and behavior: The parietal lobe syndrome in man. Res. Pub. Ass. Res. nerv. ment. Dis., 36, 35.

Douglas, A. (1963). The role of brain damage in the aetiology of squint. Little Club Clin. develop. Med., 9, 9.

Drillien, C. M. (1964). The Growth and Development of the Prematurely Born Infant. Livingstone, Edinburgh.

- Ingram, T. T. S., and Russell, E. M. (1962). Comparative aetiological studies of congenital diplegia in Scotland. Arch. Dis. Childh., 37, 282.

- - and - (1964). Further studies of the causes of diplegia in children. Develop. Med. Child Neurol., 6, 241.

Dunsdon, M. I. (1952). The Educability of the Cerebral Palsied Child. Newnes, London.

Eastman, N. J., and DeLeon, M. (1955). The etiology of cerebral palsy. Amer. F. Obstet. Gynec., 69, 950.

, Kohl, S. G., Maisel, J. E., and Kavaler, F. (1962). The obstetrical background of 753 cases of cerebral palsy. Obstet. gynec. Surv., 17, 459.

Evans, P. R., and Polani, P. E. (1950). The neurological sequelae of Rh sensitization. Quart. F. Med., 19, 129.

Fisch, L. (1955). Deafness in cerebral-palsied school-children. Lancet, 2, 370.

(1957). Hearing impairment and cerebral palsy. Speech, 21, 43.

Floyer, E. B. (1955). A Psychological Study of a City's Cerebral Palsied Children. British Council for the Welfare of Spastics, London.

Fog, E., and Fog, M. (1963). Cerebral inhibition examined by associated movements. Little Club Clin. develop. Med., 10, 52.

Forrester, R. M., and Miller, J. (1955). The dental changes associated with kernikterus. Arch. Dis. Childh., 30, 224.

Freud, S. (1891). Zur Auffassung der Aphasien. Deuticke, Leipzig and Vienna.

-(1893). Zur Kenntniss der cerebralen Diplegien des Kindesalters. Deuticke, Leipzig and Vienna.

(1897). Die infantile Cerebrallähmung. (Nothnagel's Specielle Pathologie and Therapie, div. 2, pt. 2, vol. 9.) Hölder, Vienna.

Friedreich, N. (1863). Ueber degenerative Atrophie der spinalen Hinterstränge. Virchow's Arch. path. Anat., 26, 391 and 433 and 27,1 .

(1876). Ueber Ataxie mit besonderer Berücksichtigung der hereditären Formen. ibid., 68, 145.

Fukuyama, Y., Arima, M., Nagahata, N., and Okada, A. (1963). Medical treatment of epilepsies in childhood-a long-term survey of 801 patients. Epilepsia (Amst.), 4, 207.

Gastaut, H., Poirer, F., Payan, H., Salamon, G., Toga, M., and Vigouroux, M. (1960). H. H. E. syndrome; hemiconvulsions, hemiplegia, epilepsy. ibid., 1, 418.

Gesell, A. L., and Amatruda, C. S. (1941). Developmental Diagnosis: Normal and Abnormal Child Development. Hoeber, New York.

Gibbs, F. A., Gibbs, E. L., Perlstein, M. A., and Rich, C. L. (1963). Electroencephalographic and clinical aspects of cerebral palsy. Pediatrics, 32, 73.

Glenting, P. (1963). Course and prognosis of congenital spastic hemiplegia. Develop. Med. Child Neurol., 5, 252.

Goldstein, S. L., and Burgess, J. P. (1958). Spontaneous thrombosis of the internal carotid artery in a seven-year-old child. Amer. F. Dis. Child., 95, 538.

Gowers, W. R. (1876). On 'athetosis' and post-hemiplegic disorders of movement. Med. chir. Trans., 59, 271.

Greenwald, H. M., and Messer, W. (1927). Icterus neonatorum gravis. Report of a case which recovered with sequelae pointing to an involvement of the central nervous system. Amer. F. med. Sci., 174, 793.

Griffiths, M. I., and Smith, V. H. (1963). Squint in relation to cerebral palsy. Little Club Clin. develop. Med., 8, 37. 
Guttmann, E. (1942). Aphasia in children. Brain, 65, 205.

Hansen, E. (1960). Cerebral Palsy in Denmark. Munksgaard, Copenhagen.

Henderson, J. L. (1961). Cerebral Palsy in Childhood and Adolescence. Livingstone, Edinburgh.

Holt, K. S. (1965). Assessment of Cerebral Palsy. 1. Muscle Function, Locomotion and Hand Function. Lloyd-Luke, London.

Hood, P. N., and Perlstein, M. A. (1955). Infantile spastic hemiplegia. IV. Birth weights. Pediatrics, 16, 470.

Hutchison, P. A., and Kovacs, M. C. (1963). The sequelae of acute purulent meningitis in childhood. Canad. med. Ass. $\mathcal{F}$., $89,158$.

Illingworth, R. S. (1958). Recent Advances in Cerebral Palsy. Churchill, London.

Ingram, T. T.S. (1955a). A study of cerebral palsy in the childhood population of Edinburgh. Arch. Dis. Childh., 30, 85.

- (1955b). The early manifestations and course of diplegia in childhood. ibid., 30, 244.

(1956). A characteristic form of overactive behaviour in brain damaged children. F. ment. Sci., 102, 550.

(1960). Perceptual disorders causing dyslexia and dysgraphia in cerebral palsy. Little Club Clin. develop. Med., 2, 97.

(1963). Ataxia and ataxic diplegia in childhood. ibid., 8,70 .

(1964a). Paediatric Aspects of Cerebral Palsy. Livingstone, Edinburgh.

_ (1964b). Cerebral palsy-Part I. Brit. med. F., 2, 1638. (1966). The Management of Cerebral Palsy, ed. T. T. S. Ingram, G. A. Pollock, and J. A. L. Naughton. Livingstone, Edinburgh. In the press.

- and Barn, J. (1961). A description and classification of common speech disorders associated with cerebral palsy. Cerebr. Palsy Bull., 3, 57.

- Jameson, S., Errington, J., and Mitchell, R. G. (1964). Living with cerebral palsy. Little Club Clin. develop. Med., 14.

- , and Kerr, J. D. (1954). The association of retrolental fibroplasia with cerebral diplegia. Arch. Dis. Childh., 29, 282.

- , and Naughton, J. A. (1962). Paediatric and psychological aspects of cerebral palsy associated with hydrocephalus. Develop. Med. Child Neurol., 4, 287.

—, and Russell, E. M. (1961). The reproductive histories of mothers of patients suffering from congenital diplegia. Arch. Dis. Childh., 36, 34.

Jabbour, J. T., and Lundervold, A. (1963). Hemiplegia: A clinical and electroencephalographic study in childhood. Develop. Med. Child Neurol., 5, 24.

Jeavons, P. M., and Bower, B. D. (1964). Infantile spasms. Little Club Clin. develop. Med., 15.

Kelman, H. R. (1964). The effects of a brain-damaged child on the family. In Brain Damage in Children-the Biological and Social Aspects, ed. H. G. Birch. Williams and Wilkins, Baltimore.

Klüver, H., and Bucy, P. C. (1939). Preliminary analysis of functions of the temporal lobes in monkeys. Arch. Neurol. Psychiat. (Chic.), 42, 979.

Lange, C. de (1924). Extrapyramidale Bewegungstörung bei Sepsis. Acta paediat. (Uppsala), 4, 60.

Little Club (1959). Memorandum on terminology and classification of 'cerebral palsy'. Cerebr. Palsy Bull., 1(5), 27.

Lord, E. E. (1937). Children Handicapped by Cerebral Palsy. Psychological Factors in Management. Commonwealth Fund, New York.

Lyon, G., Dodge, P. R., and Adams, R. D. (1961). The acute encephalopathies of obscure origin in infants and children. Brain, 84, 680.

MacGregor, M., Pirrie, D., and Shaddick, C. W. (1957). Cerebral palsy in the County of London. Med. Offr, 98, 367.

Magnus, R. (1926). Studies in the physiology of posture. Cameron prize lectures. Lancet, 2, 531 and 585.

Matthews, P. B. C. (1964). Central regulation of the activity of skeletal muscle. In The Role of the Gamma System in Movement and Posture, ed. I. A. Boyd et al., p. 26. Assoc. for the Aid of Crippled Children, New York. , and Rushworth, G. (1957). The selective effect of procaine on applied to its nerve. F. Physiol. (Lond.), 135, 245.

Meyers, R. (1958). Recent advances in the neurosurgery of cerebral palsy. In Recent Advances in Cerebral Palsy, ed. R. S. Illingworth, p. 330 . Churchill, London.

Michell, G. (1963). Notes on the so-called 'minimal brain damage' syndrome with particular reference to family dynamics. Little Club Clin. develop. Med., 10, 46.

Milani-Comparetti, A. (1965). La natura del difetto motorio nella paralisi cerebrale infantile. Infanz. Anorm., 64, 597.

Miller, H. G., and Stanton, J. B. (1954). Neurological sequelae of prophylactic inoculation. Quart. F. Med., 23, 1.

, - and Gibbons, J. L. (1956). Para-infectious encephalomyelitis and related syndromes. ibid., 25, 427.

Minear, W. L. (1956). A classification of cerebral palsy. Pediatrics, $18,841$.

Minkowski, M. (1955). Prenatal neuropathologic changes leading to neurologic or mental disorders. In Proc. 1st International Congress of Neuropathology, Rome, 1952, vol. 2, p. 51 . Rosenberg \& Sellier, Turin.

Mitchell, R. G. (1952). Venous thrombosis in acute infantile hemiplegia. Arch. Dis. Childh., 27, 95.

(1961a). The definition and classification of cerebral palsy. In Cerebral Palsy in Childhood and Adolescence, ed. J. L. Henderson, p. 25. Livingstone, Edinburgh.

(1961b). Analysis of each type of cerebral palsy. ibid., p. 73.

(1962). The early recognition of acute hemiplegia in childhood. Little Club Clin. develop. Med., 6, 58.

Monakov, C. von (1901). Ueber die Missbildungen des Centralnervensystems. Ergebn. allg. Path. path. Anat., 6, 513. (1926). Biologisches und morphogenetisches: über die mikrocephalia vera. Schweiz. Arch. Neurol. Psychiat., 18, 3.

Mowat, J. (1961). Ear, nose and throat disorders: deafness. In Cerebral Palsy in Childhood and Adolescence, ed. J. L. Henderson, p. 242. Livingstone, Edinburgh.

Nelson, T. M. (1962). A study comparing visual and visuo-motor perceptions of unimpaired, defective and spastic cerebral palsied children. F. genet. Psychol., 101, 299.

Nielsen, H. H. (1962). Visual motor functioning of cerebral palsied and normal children. Nord. Psykol., 14, 41.

Norman, R. M. (1963). Observations on the neuropathology of cerebellar disease in early life. Little Club Clin. develop. Med., $8,49$.

Nyhan, W. L., and Richardson, F. (1963). Complications of meningitis. Ann. Rev. Med., 14, 243.

Oppé, T., and Paine, R. S. (1966). The neurological examination of the child. Little Club Clin. develop. Med. In the press.

Ounsted, C. (1955). The hyperkinetic syndrome in epileptic children. Lancet, 2, 303.

Paine, R. S., Brazelton, T. B., Donovan, D. E., Drorbaugh, J. E., Hubbell, J. P., Jr., and Sears, E. M. (1964). Evolution of postural reflexes in normal infants and in the presence of chronic brain syndromes. Neurology (Minneap.), 14, 1036.

Pederson, E. (1964). Postencephalitic epilepsy. Epilepsia (Amst.), $5,43$.

Peiper, A. (1964). Cerebral Function in Infancy and Childhood. Translation of the 3rd Revised German Edition by B. Nagler and $H$. Nagler. Pitman, London.

Perlstein, M. A. (1952). Infantile cerebral palsy; classification and clinical correlations. f. Amer. med. Ass., 149, 30.

- Gibbs, E. L., and Gibbs, F. (1953). The electroencephalogram in infantile cerebral palsy. In Proc. of the Meeting of the Academy for Cerebral Palsy. Williams and Wilkins, Baltimore. , and (1955). The electroencephalogram in infantile cerebral palsy. Amer. f. phys. Med., 34, 477.

, and Hood, P. N. (1954). Infantile spastic hemiplegia. I. Incidence. Pediatrics, 14, 436.

Phelps, W. M. (1941). The rehabilitation of cerebral palsy. Sth. med. F. (Bgham, Ala.), 34, 770.

(1943). The treatment of cerebral palsies: description of the athetoid type. Clinics, 2, 981.

- (1948). Characteristic psychological variations in cerebral palsy. Nerv. Child, 7, 10.

Plum, P. (1965). Aetiology of athetosis with special reference to neonatal asphyxia, idiopathic icterus and ABO-incompatibility. Arch. Dis. Childh., 40, 376.

Prechtl, H. F. R. (1960). The long term value of the neurological examination of the newborn infant. Little Club Clin. develop. Med., 2, 69.

(1962). Reading difficulties as a neurological problem in childhood. In Reading Disability: Progress and Research Needs in Dyslexia, ed. J. Money. Johns Hopkins Press, Baltimore. 
- and Beintema, D. (1964). The neurological examination of the full-term newborn infant. Little Club Clin. develop. Med. 12.

- , and Dijkstra, J. (1960). Neurological diagnosis of cerebral injury in the new-born. In Prenatal Care, p. 222. Noordhoff, Grönigen.

Rushworth, G. (1959). The nature of the functional disorder in the hypertonic states. Cerebr. Palsy Bull., 1(7), 3.

- (1960). Spasticity and rigidity: An experimental study and review. F. Neurol. Neurosurg. Psychiat., 23, 99.

(1962). Muscle tone and the muscle spindle in clinical neurology. In Modern Trends in Neurology, ser. 3, ed. D. Williams. Butterworth, London.

-, and Denny-Brown, D. (1959). The two components of the grasp reflex after ablation of the frontal cortex in monkeys. f. Neurol. Neurosurg. Psychiat., 22, 91.

Russell, E. M. (1960a). Correlation between birth weight and clinical findings in diplegia. Arch. Dis. Childh., 35, 548. (1961). Cerebral palsied twins. ibid., 36, 328.

Russell, W. R. (1960b). The parietal lobes. Little Club Clin. develop. Med., 2, 110.

Sachs, B., and Hausman, L. (1926). Nervous and Mental Disorders from Birth through Adolescence. Hoeber, New York.

Sandifer, P. (1962). Non-vascular causes of acute hemiplegia in childhood. Little Club Clin. develop. Med., 6, 17.

Schutt, W. (1963). Clinical and genetic aspects of congenital cerebellar ataxia. ibid., 8, 83.

Sheridan, M. (1965). Paper given to the Spastic Society Study Group on Visual Disorders in Edinburgh.

Sherrington, C. (1906, 1947). The Integrative Action of the Nervous System. 1st ed.: Constable, London; 2nd ed.: Cambridge University Press, London.

Skatvedt, M. (1958). Cerebral palsy: a clinical study of 370 cases. Acta paediat. (Uppsala), 46, Suppl. 111.

Smith, E. S. (1954). Purulent meningitis in infants and children. A review of 409 cases. F. Pediat., 45, 425.

Smith, V. H. (1963). A survey of strabismus in cerebral palsy. Little Club Clin. develop. Med., 9, 22.

Stark, G. (1966). Rubella retinopathy: An account of six cases. Arch. Dis. Childh., 41, 420.

Strauss, A. A., and Lehtinen, L. E. (1947). Psychopathology and Education of the Brain-Injured Child. Grune and Stratton, New York.

Tardieu, C., Tardieu, G., Hariga, J., Gagnard, L., and Velin, J. (1964). Fondement expérimental d'une thérapeutique des raideurs d'origine cérébrale. Arch. franc. Pediat., 21, 5.

Tardieu, G., and Hariga, J. (1964). Traitement des raideurs musculaires d'origine cérébrale par infiltration d'alcool dilué. ibid., 21, 25.

Taylor, E. M. (1959). Psychological Appraisal of Children with Cerebral Defects. Harvard University Press, Cambridge, Massachusetts.
Thomas, A., and Saint Anne Dargassies, S. (1952). Études Neurologiques sur le Nouveau-né et le feune Nourisson. Masson, Paris.

—, Chesni, Y., and Saint Anne Dargassies, S. (1960). The neurological examination of the infant. Little Club Clin. develop. Med., 1.

Till, K., and Hoare, R. D. (1962). Cerebral angiography in investigation of acute hemiplegia. ibid., 6, 69.

Tizard, J. P. M. (1964). Neuromuscular disorders of infancy. In Disorders of Voluntary Muscle, ed. John N. Walton, p. 369. Churchill, London.

- Paine, R. S., and Crothers, B. (1954). Disturbances of sensation in children with hemiplegia. F. Amer. med. Ass., 155, 628.

Todd, R. M., and Neville, J. G. (1964). The sequelae of tuberculous meningitis. Arch. Dis. Childh., 39, 213.

Twitchell, T. E. (1951). The restoration of motor function following hemiplegia in man. Brain, 74, 443.

- (1957). The prognosis of motor recovery in hemiplegia. Bull. Tufts-New Engl. med. Cent., 3, 146.

- (1958). The grasping deficit in infantile spastic hemiparesis. Neurology (Minneap.), 8, 13.

Walshe, F. M. R. (1923). The decerebrate rigidity of Sherrington in man-its recognition and differentiation from other forms of tonic muscular contraction. Arch. Neurol. Psychiat. (Chic.), 10, 1.

- (1924). Observations on the nature of the muscular rigidity of paralysis agitans, and on its relationship to tremor. Brain, 47 , 159.

Wedell, K. (1960). The visual perception of cerebral palsied children. F. Child. Psychol., 1, 215.

Wood, B. S. B. (1964). Complications of pyogenic meningitis. Develop. Med. Child Neurol., 6, 63.

Woods, G. E. (1957). Cerebral Palsy in Childhood. Wright, Bristol.

(1965). Some clinical notes on electroencephalographic findings in cerebral palsy. Arch. Dis. Childh., 40, 394.

Wortis, H., and Cooper, W. (1957). The life experiences of persons with cerebral palsy. Amer. F. phys. Med., 36, 328.

Wuillamier, T. (1882). De l'Épilepsie dan l'Hémiplégie Spasmodique Infantile. Thèse de Paris.

Yakovlev, P. I., and Wadsworth, R. C. (1946). SchizencephaliesA study of the congenital clefts in the cerebral mantle. $f$. Neuropath. exp. Neurol., 5, 169.

Yannet, H. (1949). Infantile cerebral palsy cases with severe mental deficiency: relationship of etiology to type of neurologic syndrome. Pediatrics, 3, 820.

Zappella, M. (1964). Postural reactions in 100 children with cerebral palsy and mental handicap. Develop. Med. Child Neurol., 6, 475. 